\title{
Disruption of integrin-fibronectin complexes by allosteric but not ligand-mimetic inhibitors
}

A. Paul Mould ${ }^{* 1}$, Susan E. Craig ${ }^{\dagger}$, Sarah K. Byron†, Martin J. Humphries ${ }^{\dagger}$ and Thomas A. Jowitt ${ }^{*}$

\section{BJ BIOMOLECULES}

*Biomolecular Analysis Core Facility and +Wellcome Trust Centre for Cell-Matrix Research Faculty of Life Sciences, Michael Smith Building, University of Manchester, Oxford Road, Manchester, M13 9PT, U.K.

${ }^{1}$ To whom correspondence should be addressed (email: paul.mould@manchester.ac.uk). Tel 01612756196

Key words: allostery, antagonist, fibronectin, integrin, RGD motif, therapeutics

Short Title: Disruption of Integrin Function by Allosteric Inhibitors 


\title{
Summary Statement
}

Integrins are protein receptors on cells, and inhibiting these receptors is a strategy for treating many diseases. We show that commonly-used integrin inhibitors are unable to dissociate preformed integrin-ligand complexes, whereas inhibitors that function allosterically are able to do so.

\begin{abstract}
Failure of Arg-Gly-Asp (RGD)-based inhibitors to reverse integrin-ligand binding has been reported, but the prevalence of this phenomenon among integrin heterodimers is currently unknown. Here we have studied the interaction of four different RGD-binding integrins $(\alpha 5 \beta 1, \alpha \mathrm{V} \beta 1, \alpha \mathrm{V} \beta 3$ and $\alpha \mathrm{V} \beta 6$ ) with fibronectin (FN) using surface plasmon resonance. The ability of inhibitors to reverse ligand binding was assessed by their capacity to increase the dissociation rate of preformed integrin-FN complexes. For all four receptors we show that RGD-based inhibitors (such as cilengitide) were completely unable to increase the dissociation rate. Formation of the non-reversible state occurred very rapidly and did not rely on the time-dependent formation of a high affinity state of the integrin, or the integrin leg regions.
\end{abstract}

In contrast to RGD-based inhibitors, $\mathrm{Ca}^{2+}$ (but not $\mathrm{Mg}^{2+}$ ) was able to greatly increase the dissociation rate of integrin-FN complexes, with a half-maximal response at $\sim 0.4 \mathrm{mM} \mathrm{Ca}^{2+}$ for $\alpha \mathrm{V} \beta 3-\mathrm{FN}$. The effect of $\mathrm{Ca}^{2+}$ was overcome by co-addition of $\mathrm{Mn}^{2+}$ but not $\mathrm{Mg}^{2+}$. A stimulatory anti- $\beta 1$ monoclonal antibody (mAb) abrogated the effect of $\mathrm{Ca}^{2+}$ on $\alpha 5 \beta 1-\mathrm{FN}$ complexes; conversely, a function-blocking mAb mimicked the effect of $\mathrm{Ca}^{2+}$. These results imply that $\mathrm{Ca}^{2+}$ acts allosterically, probably through binding to the adjacent to metal-ion dependent adhesion site (ADMIDAS), and that the $\alpha 1$ helix in the $\beta$ subunit I domain is the key element affected by allosteric modulators. The data suggest an explanation for the limited clinical efficacy of RGD-based integrin antagonists, and we propose that allosteric antagonists could prove of greater therapeutic benefit. 
Footnotes:

${ }^{2}$ We use the term "non-reversible" to mean a ligand-bound state of the integrin that cannot be disrupted by ligand-mimetic inhibitors, whether at short or extended time points, and "timestabilised state" to mean a state formed at extended time points that has very low dissociation rate (termed "irreversible" in some publications).

Abbreviations: $\alpha 5 \beta 1-\mathrm{Fc}$ recombinant soluble integrin heterodimer containing the complete ectodomains of the $\alpha_{5}$ and $\beta_{1}$ subunits fused to the Fc region of IgG $\gamma 1$ chain; ADMIDAS, adjacent to metal-ion dependent adhesion site; $\beta \mathrm{I}, \beta$ subunit I/A domain; FN, fibronectin; $\mathrm{mAb}$, monoclonal antibody; MIDAS, metal-ion dependent adhesion site; RBMn, running buffer with $1 \mathrm{mM} \mathrm{MnCl}_{2}$; RB0, running buffer without $\mathrm{MnCl}_{2}$; RGD, Arg-Gly-Asp; SyMBS, synergistic metal binding site; rs, recombinant soluble; SPR, surface plasmon resonance; TR $\alpha_{5} \beta_{1}-\mathrm{Fc}$, recombinant soluble integrin heterodimer containing the head region of the $\alpha_{5}$ and $\beta_{1}$ subunits fused to the $\mathrm{Fc}$ region of $\operatorname{IgG} \gamma 1$ chain. 


\section{INTRODUCTION}

Integrins are a large family of $\alpha, \beta$ heterodimeric receptors for extracellular matrix and cellsurface proteins [1]. Integrins are validated therapeutic targets in oncogenic, thrombotic and autoimmune disorders [2,3]. A large subset of integrins comprises those that recognize the Arg-Gly-Asp (RGD) sequence in their ligands $(\alpha 3 \beta 1, \alpha 5 \beta 1, \alpha 8 \beta 1, \alpha \mathrm{V} \beta 1, \alpha \mathrm{V} \beta 3, \alpha \mathrm{IIb} \beta 3$, $\alpha \mathrm{V} \beta 5, \alpha \mathrm{V} \beta 6$ and $\alpha \mathrm{V} \beta 8$ ). Many of these receptors recognize this site in the prototypical integrin ligand fibronectin (FN). Ligand-mimetic RGD-based compounds (e.g. cilengitide) act as competitive antagonists, and have been developed for treatment of cancer [4,5].

The overall structure of integrins is that of a large 'head' region supported by two long 'legs' [6,7]. The head region includes the $\beta$-propeller domain of the $\alpha$ subunit and the $\beta$ I and hybrid domain of the $\beta$ subunit. At least three major conformational states of integrins have been identified: a closed form with bent legs and closed headpiece, an intermediate form with extended legs and closed headpiece, and an open form with extended legs and open headpiece [8-10]. These three states correspond to states of low, intermediate and high affinity, respectively [11]. Opening of the headpiece involves shifts of the $\alpha 1$ and $\alpha 7$ helices in the $\beta I$ domain, and an outward swing of the hybrid domain away from the $\beta$-propeller [7, 12-16]. Loops on the upper surface of the $\beta$-propeller and the top face of the $\beta$ I domain form the ligand-binding pocket [16-19].

The top face of $\beta$ I contains three structurally interlinked bivalent cation-binding sites: the metal-ion dependent adhesion site (MIDAS), the ADMIDAS (adjacent to MIDAS), and SyMBS (synergistic metal-binding site; also known as LIMBS) [6,7,20]. The bivalent ions $\mathrm{Mn}^{2+}, \mathrm{Mg}^{2+}$ and $\mathrm{Ca}^{2+}$ each have distinct effects on integrin affinity and conformational state through binding to these sites. $\mathrm{Mn}^{2+}$ or $\mathrm{Mg}^{2+}$ (or more rarely $\mathrm{Ca}^{2+}$ ) occupancy of the MIDAS is critical for ligand recognition through coordinating to a carboxyl oxygen, such as in the side chain of Asp in ligands containing the RGD sequence [16,17]. $\mathrm{Ca}^{2+}$ has multiple effects on ligand binding and can be stimulatory or inhibitory, dependent on the $\mathrm{Ca}^{2+}$ concentration and whether $\mathrm{Mn}^{2+}$ or $\mathrm{Mg}^{2+}$ is also present $[21,22]$. The SyMBS mediates the positive effects of low concentrations of $\mathrm{Ca}^{2+}$ on $\mathrm{Mg}^{2+}$-supported ligand binding, whereas the ADMIDAS mediates the negative effects of higher $\mathrm{Ca}^{2+}$ concentrations on $\mathrm{Mn}^{2+}$-supported ligand binding [23-26]. $\mathrm{Mn}^{2+}$ binding promotes the formation of the open form of the headpiece, whereas $\mathrm{Ca}^{2+}$ favours the closed headpiece $[13,20]$.

Receptor-ligand binding can involve either induced-fit (the binding of ligand to a low affinity form of the receptor, which then converts to a high affinity form) or selected-fit (the binding of ligand to a high affinity state of the receptor, in preference to a low affinity state) interactions [27]. There is evidence to support both types of interaction for RGD-binding integrins [16] but there is considerable debate concerning the relative importance of each type $[11,16]$. In addition, a high affinity, non-reversible ${ }^{2}$ form of $\alpha \mathrm{V} \beta 3$ and $\alpha \operatorname{IIb} \beta 3$ bound to their ligands has been reported [28-32]. A study by Orlando and Cheresh [28] established that (i) macromolecular ligands but not RGD peptides bind to $\alpha \mathrm{V} \beta 3$ in a stabilized manner (dissociation rate, $\mathrm{k}_{\mathrm{d}}$, close to zero), (ii) after macromolecular ligand binding has taken place excess soluble ligand or RGD peptides are unable to dissociate the complex, and (iii) a conformational change in the integrin is necessary for binding to become stabilized.

It is not currently understood if non-reversible states are a common feature of integrin-ligand interactions, how rapidly they form, what regions of the integrin are implicated, the nature of the conformational changes involved, and the role (if any) of bivalent cations. Here we 
examine the binding in real time of four different RGD-binding integrins to a fragment of FN using surface plasmon resonance (SPR). We demonstrate that the binding of each integrin to $\mathrm{FN}$ is non-reversible by RGD-based inhibitors. Formation of the non-reversible state is very fast, and not related to the slow formation of a state with very low dissociation rate. Our data suggest that formation of the non-reversible state is dependent on conformational changes within the $\beta$ I domain, and perturbing these changes with allosteric inhibitors leads to rapid dissolution of the integrin-ligand complex. Based on these findings, we propose that allosteric integrin antagonists could have potent therapeutic benefit. 


\section{EXPERIMENTAL}

\section{Materials}

The production of recombinant integrin $\alpha 5 \beta 1-\mathrm{Fc}$ and its truncated form TR $\alpha 5 \beta 1-\mathrm{Fc}$ has been previously described $[26,32]$. Briefly, $\alpha 5 \beta 1-\mathrm{Fc}$ and TR $\alpha 5 \beta 1-\mathrm{Fc}$ were produced in NS0 cells and purified using Protein A Sepharose. TR $\alpha 5 \beta 1-\mathrm{Fc}$ was further purified by affinity chromatography on $50 \mathrm{~K}$-Sepharose. Both integrins were then purified by gel-filtration chromatography using Superose 6 (GE Healthcare). Recombinant integrin $\alpha$ V $\beta 3 \Delta$ TM [6] was a gift from S. Goodman (Merck Serono, Darmstadt, Germany). Recombinant soluble (rs) integrins $\alpha \mathrm{V} \beta 1$ and $\alpha \mathrm{V} \beta 6$ were produced in a baculovirus expression system in High Five ${ }^{\mathrm{TM}}$ cells [33]. In brief, cDNA of full-length ectodomains of $\alpha \mathrm{V}$ and $\beta 1$, or $\alpha \mathrm{V}$ and $\beta 6$ were cloned into the pFastBact ${ }^{\mathrm{TM}}$ Dual vector (Life Sciences). The C-termini of the $\alpha \mathrm{V}$ and $\beta$ subunits were extended with the Fos leucine zipper motif and His 6 tag, and the Jun leucine zipper motif and FLAG® tag, respectively (constructs were a gift from S. Ludbrook, GlaxoSmithKline, Stevenage, United Kingdom). Bacmid DNA was isolated from DH10BAC E.coli cells, following transformation with the pFastBactTM Dual $\alpha \mathrm{V} \beta 1$ and $\alpha \mathrm{V} \beta 6$ vectors, and used to transfect $S f 9$ cells. Upon transfection, the $S f 9$ cells produced recombinant baculovirus which was subsequently amplified to generate high titre baculovirus. A suspension culture of High Five ${ }^{\mathrm{TM}}$ cells was infected with recombinant baculovirus at a multiplicity of infection (MOI) of 5 and then cultured using a Wave ${ }^{\mathrm{TM}}$ bioreactor (GE Healthcare Life Sciences) or in 2 litre conical flasks (Corning) for $72 \mathrm{~h}$ at $28{ }^{\circ} \mathrm{C}$. The cell culture supernatant was then concentrated and diafiltrated using tangential flow filtration. Soluble integrin was purified first using Ni-NTA agarose (Qiagen) and then by anti-FLAG® agarose (Sigma). rs $\alpha \mathrm{V} \beta 6$ was further purified using Superose 6. LC-MS/MS analysis confirmed that the integrin proteins were isolated to a high degree of purity. Both $\operatorname{rs} \alpha \mathrm{V} \beta 1$ and rs $\alpha \mathrm{V} \beta 6$ bound strongly to fibronectin in solid phase assays [33].

Monclonal antibody (mAb) TS2/16 was a gift from F. Sánchez-Madrid (Hospital de la Princesa, Madrid, Spain). N29 was a gift from J. Wilkins (University of Manitoba, Winnipeg, Canada), mAb 13 was a gift from K. Yamada (National Institutes of Health, Bethesda, MD, USA), 4B4 was from Beckman Coulter, $8 \mathrm{E} 3$ has been previously described $[10,34]$. Fab fragments of TS2/16 and N29 were produced by ficin cleavage as previously described [13].

The 50-kDa cell-binding domain fragment of human fibronectin (3Fn6-10; '50K') and a mutant in which the RGD sequence was converted to KGE (50K-KGE) were produced in $E$. coli and purified as before $[18,35] .50 \mathrm{~K}$ and $50 \mathrm{~K}-\mathrm{KGE}$ were biotinylated using maleimide$\mathrm{PEG}_{2}$-biotin (Thermo Scientific) and purified by gel-filtration using Superdex 200 (10/30, GE Healthcare) to remove unreacted cross-linker and any multimers. Both proteins contain a single site for biotinylation in 3Fn7. Peptide GCRGDSPCG (cRGD) was purchased from Peptide 2.0 Inc. (Chantilly, VA, USA) and cyclized by oxidation as previously described [18]. Cilengitide was a gift from D. Cheresh, (Department of Pathology and Moores UCSD Cancer Center, USCD, La Jolla, CA, USA). Avidin (from egg-white) was obtained from Life Technologies.

\section{Surface plasmon resonance}

Experiments were performed using the ProteOn XPR36 instrument (Bio-Rad Laboratories).

Running buffer was $150 \mathrm{mM} \mathrm{NaCl}, 10 \mathrm{mM}$ Hepes, 0.02\% (w/v) Tween-20, pH 7.4 with 1mM $\mathrm{MnCl}_{2}(\mathrm{RBMn})$, except where otherwise indicated. Running buffer without $\mathrm{MnCl}_{2}$ is referred 
to as RB0. Immobilization of avidin was performed on a GLC chip (Bio-Rad Laboratories) in the vertical orientation. Two channels were activated with $150 \mu 1$ of $25 \mathrm{mM} \mathrm{N}$-ethyl- $N^{\prime}-(3-$ dimethylaminopropyl) carbodiimide (EDC) followed immediately by $8 \mathrm{mM}$ sulfo- $N$ hydroxysuccinimide (sulfo-NHS) at a flow rate of $30 \mu \mathrm{l} / \mathrm{min}$ using the 'coinject ligand' command. Avidin was diluted in running buffer to a final concentration of $1.2 \mu \mathrm{M}$, and $150 \mu \mathrm{l}$ was injected, followed by an injection of $150 \mu \mathrm{l}$ of $1 \mathrm{M}$ ethanolamine- $\mathrm{HCl}(\mathrm{pH} 8.5)$ at a flow rate of $30 \mu \mathrm{l} / \mathrm{min}$. The immobilization level of avidin was approximately 3200 resonance units (RU). Next, $150 \mu \mathrm{l}$ of $50 \mathrm{~K}-\mathrm{KGE}$ in one channel and $50 \mathrm{~K}$ in the second (20-200 nM) in running buffer were injected to allow their capture by the immobilized avidin. Immobilization levels were in the range 50-600 RU, as required for different integrins. Injection of $50 \mathrm{~K}$ and $50 \mathrm{~K}-\mathrm{KGE}$ was repeated as necessary to give equivalent immobilisation levels of the two proteins. Typically, a low surface density of the 50K-KGE was bound to the chip surface on L1 (reference channel) and an equivalent low density of $50 \mathrm{~K}$ was bound on L2 (ligand channel) [36]. All experiments were performed at $25^{\circ} \mathrm{C}$. For further details of Proteon XPR36, kinetic measurements and analysis see Supplementary Data.

To test the effect of cilengitide, cRGD or ETDA on the dissociation rate of integrin-50K complexes, $100 \mu \mathrm{l}$ integrin in RBMn was injected in three parallel horizontal channels at $50 \mu \mathrm{l} / \mathrm{min}$ and binding to $50 \mathrm{~K}$ was allowed to occur for $120 \mathrm{~s}$, followed by injection of RBMn for $60 \mathrm{~s}$; next either RBMn alone (channel 1), or RBMn with inhibitor (channel 2) was injected for $120 \mathrm{~s}$, followed by a return to RBMn alone. The concentration of inhibitor used was the same as that which resulted in zero $50 \mathrm{~K}$ binding if added to the integrin prior to the initial injection period (channel 3). The three-stage injection described above (integrinbuffer-inhibitor) was accomplished using the 'Coinject analyte' command. The buffer acts as a barrier between the integrin and inhibitor solutions and helps to prevent mixing between the two. Injection quality was set at 'maximum'. Integrin concentrations used were $6 \mathrm{nM}$ for $\alpha 5 \beta 1-\mathrm{Fc}, 50 \mathrm{nM} \alpha \mathrm{V} \beta 1, \alpha \mathrm{V} \beta 3$ and $\alpha \mathrm{V} \beta 6$, and $40 \mathrm{nM}$ for TR $\alpha 5 \beta 1-\mathrm{Fc}$, except were indicated otherwise.

Similar methods were used in other experiments and further details are given in Figure legends.

\section{Data analysis}

All binding sensorgrams were collected, processed, and analysed using the integrated ProteOn Manager software (Bio-Rad Laboratories). Short black segments on some sensorgrams represent artefact (spike) removal from the data. Except where stated otherwise, dissociation rates were calculated using off-rate analysis (ProteOn Manager software) with the equation:

$\mathrm{A}=\mathrm{A}_{0} * \exp \left(-\mathrm{k}_{\mathrm{d}} *\left(\mathrm{t}-\mathrm{t}_{0}\right)\right)$

where $\mathrm{A}_{0}=$ binding at $\mathrm{t}_{0}$.

For analysis of the effect of $\mathrm{Ca}^{2+}$ on $\mathrm{Mn}^{2+}$-supported ligand binding, dissociation rates $\left(\mathrm{k}_{\mathrm{d}}\right.$ values) were obtained from the binding data using the equation:

$A=\left(A_{0}-A_{e q}\right) * \exp \left(-k_{d} *\left(t-t_{0}\right)\right)+A_{e q}$

where $\mathrm{A}_{0}=$ binding at $\mathrm{t}_{0}(207.9 \mathrm{~s}), \mathrm{A}_{\mathrm{eq}}=$ binding at equilibrium, and $\mathrm{t}=207.9-320.4 \mathrm{~s}$ 
To estimate the concentration of $\mathrm{Ca}^{2+}$ for half-maximal effect, dissociation rates were then plotted against $\left[\mathrm{Ca}^{2+}\right]$ and fitted for apparent $\mathrm{K}_{\mathrm{D}}$ and maximal dissociation rate $\left(\mathrm{D}_{\max }\right)$ using the equation:

$\mathrm{D}=\left(\mathrm{D}_{\max } *\left[\mathrm{Ca}^{2+}\right] /\left(\mathrm{K}_{\mathrm{D}}+\left[\mathrm{Ca}^{2+}\right]\right)\right)+\mathrm{D}_{0}$

where $\mathrm{D}_{0}=$ Dissociation rate at zero $\left[\mathrm{Ca}^{2+}\right]$.

To estimate the concentration of $\mathrm{Mn}^{2+}$ for half-maximal blockade of the inhibitory effect of $\mathrm{Ca}^{2+}$ dissociation rates were plotted versus $\left[\mathrm{Mn}^{2+}\right]$ and fitted for $\mathrm{D}_{\min }, \mathrm{D}_{\max }$ and ' $\mathrm{I} \mathrm{C}_{50}$ ' value using the equation:

$\mathrm{D}=\mathrm{D}_{\min }+\left(\mathrm{D}_{\max }-\mathrm{D}_{\min }\right) /\left(1+10^{\wedge}\left(\log \left(\left[\mathrm{Mn}^{2+}\right]\right)-\log \left(\mathrm{IC}_{50}\right)\right)\right)$

where $\mathrm{D}_{\min }=$ dissociation rate at infinite $\mathrm{Mn}^{2+}$ concentration, $\mathrm{D}_{\max }=$ Dissociation rate at zero $\left[\mathrm{Mn}^{2+}\right]$.

Curves were fitted using global optimization by simulated annealing (GOSA-fit, www.biolog.biz).

All results shown are representative of at least three separate experiments. 


\section{RESULTS}

\section{Kinetics of integrin-FN binding}

For these studies we utilised four different recombinant RGD-binding integrins $(\alpha 5 \beta 1, \alpha \mathrm{V} \beta 1$, $\alpha \mathrm{V} \beta 3$ and $\alpha \mathrm{V} \beta 6$ ), and a fragment of FN, termed ' $50 \mathrm{~K}$ ' [18], as the ligand. The Proteon XPR36 instrument was utilised for SPR measurements [37,38]. To measure kinetics we used a short association phase, followed by a long dissociation phase. The results (Figure 1) showed that each integrin interacted with $50 \mathrm{~K}$ but had differing dissociation rates. In each case, however, a biphasic dissociation phase was observed in which the dissociation rate in the early part of the dissociation phase was higher than that in the later part (Table 1). These data suggest either that the integrin samples contain a mixture of states with one form having a high dissociation rate and another having a low dissociation rate, or that a form of the integrin with high dissociation rate is gradually converted to a form with a low dissociation rate. To attempt to discriminate between these two possibilities, we fitted the data to either a selected fit (heterogenous analyte) model (Figure 2A-D), or an induced fit (two-state) model (Figure 2E-H), see also Supplementary Tables 1 and 2 . The two models fitted the data equally well (with essentially identical $\chi^{2}$ values), whereas a simple 1:1 model (with a monophasic dissociation phase) fitted poorly (Figure 2I-L). Although we could not distinguish between the selected fit and induced fit models based on the above analyses, we found that at longer time periods after the association phase the dissociation rate became progressively lower (for example, $\mathrm{k}_{\mathrm{d}} \sim 10^{-5} \mathrm{~s}^{-1}$ at $6 \mathrm{~h}$ for $\alpha 5 \beta 1-\mathrm{Fc}$, data not shown), suggesting that time-dependent stabilisation of a high affinity state does play some role in these interactions.

\section{Integrin-FN complexes are non-reversible by RGD-based peptides}

To investigate the effect of reagents on pre-formed integrin-FN complexes we used the following procedure: integrin binding to $50 \mathrm{~K}$ was allowed to occur for $120 \mathrm{~s}$, followed by injection of running buffer alone for $60 \mathrm{~s}$; next either running buffer alone, or running buffer with inhibitor was injected for $120 \mathrm{~s}$, followed by a return to running buffer. The concentration of inhibitor used was the same as that which resulted in zero binding to $50 \mathrm{~K}$ if added to the integrin before the association phase (see legend to Fig. 3). The primary RGDbased inhibitor we used was cilengitide, a cyclic peptide containing the RGDf $(N-\mathrm{Me}) \mathrm{V}$ sequence [4]. The second was a cyclic peptide (cRGD) containing the GRGDSP sequence from FN [18]. We found that neither RGD-based antagonist increased the dissociation rate of integrin-FN complexes (Fig. 3), similar results were obtained at ten times higher inhibitor concentrations (data not shown). Since addition of the inhibitor took place only 1 min after the end of the association phase our data indicate that it is not necessary for a time-stabilised state to form before complexes become resistant to the effect of such antagonists. In addition, the observation that those integrin-FN complexes with fast initial dissociation rates $(\alpha \mathrm{V} \beta 1$ and $\alpha \mathrm{V} \beta 6$ ) were unaffected by RGD-based inhibitors suggests that non-reversibility is also a feature of low affinity states.

\section{Effect of EDTA on the dissociation of integrin-FN complexes}

We next investigated whether EDTA, which is known to disrupt integrin-ligand interactions by removal of the metal ion at the MIDAS site, could dissociate the integrin-FN complexes. Experiments were performed in essentially the same way as described above, except that running buffer with $5 \mathrm{mM}$ EDTA was injected during the dissociation phase in place of RGD-based peptides. The results (Figure 4) showed that EDTA could very rapidly disrupt 
$\alpha \mathrm{V} \beta 1-$ and $\alpha \mathrm{V} \beta 6-\mathrm{FN}$ complexes, and more slowly $\alpha 5 \beta 1-\mathrm{FN}$ complexes. In contrast, $\alpha \mathrm{V} \beta 3$-FN complexes were resistant to the effect of EDTA, and we observed only a 1.5-fold increase in the dissociation rate in the presence of $5 \mathrm{mM}$ EDTA (see Figure 4 legend). As a control, no binding to $50 \mathrm{~K}$ was observed if EDTA was added to each integrin before the association phase (Figure 4).

\section{The integrin head region is sufficient for non-reversibility}

To investigate what regions of the integrin are required for non-reversible binding we utilised a truncated construct of $\alpha 5 \beta 1-\mathrm{Fc}$ (termed TR $\alpha 5 \beta 1-\mathrm{Fc}$ ) that contains only the head region of $\alpha 5$ and $\beta 1$ subunits [26,32]. We have previously shown that this protein is of lower constitutive activity than the $\alpha 5 \beta 1-\mathrm{Fc}$ construct (used above) that contains the full-length ectodomains [32]. We tested binding of this construct to 50K as described above (Figure 5A). The results showed that the dissociation phase was very clearly biphasic (or multiphasic) with a fast initial off-rate and a very slow final off-rate (Table I). In agreement with previous results that the interaction of $\mathrm{TR} \alpha 5 \beta 1-\mathrm{Fc}$ with $\mathrm{FN}$ is weaker [32], the initial dissociation rate was markedly faster than that for $\alpha 5 \beta 1-\mathrm{Fc}$. However, a component with high affinity binding was observed at later time points. We fitted the kinetic data to either a heterogenous analyte model, or a two-state model (Figure 5B, C; Supplementary Tables I and II). Both models fitted the data well, whereas a 1:1 model did not (Figure 5D). However, the marked differences between the initial and final dissociation rates made this system suitable for discriminating between the two-state and heterogeneous models by testing the effect of varying the length of the association phase on the subsequent dissociation phase (Figure 5E). The data showed that the proportion of the slowly dissociating component increased as the association time increased, consistent with time-dependent stabilisation of a high affinity state (two-state model) for this complex.

We next examined whether RGD-based inhibitors or EDTA could dissociate TR $\alpha 5 \beta 1-\mathrm{FN}$ complexes, using the same procedures described above. The results (Figure 5F-H) showed that the complexes could not be dissociated by RGD-based inhibitors, although they were readily dissociated by EDTA. Hence, the head region alone is sufficient to make ligand binding non-reversible by RGD-based peptides. In addition, since the peptides were added during the early part of the dissociation phase, these data also provide further evidence that a high affinity form of the integrin is not required for ligand binding to become non-reversible.

\section{Effect of bivalent cations on the reversibility of $\alpha \mathrm{VB3}-\mathrm{FN}$ complexes by RGD-based peptides}

We focussed mainly on $\alpha \mathrm{V} \beta 3$ for studies of the role of bivalent cations in non-reversible binding because of the resistance of $\alpha \mathrm{V} \beta 3-\mathrm{FN}$ complexes to dissociation by EDTA. This property indicates that the MIDAS cation is very stably bound in the complex, and hence unlikely to be lost, or replaced by other bivalent ions, during the dissociation phase.

In the first series of experiments we tested if $\alpha \mathrm{V} \beta 3-\mathrm{FN}$ complexes were reversible by RGDbased peptides if $\mathrm{Mg}^{2+}$ or $\mathrm{Ca}^{2+}$, rather than $\mathrm{Mn}^{2+}$, was used as the supporting bivalent ion. Both $\mathrm{Mg}^{2+}$ and $\mathrm{Ca}^{2+}$ enabled $\mathrm{FN}$ binding although the initial dissociation rate in $\mathrm{Ca}^{2+}$ was much faster than that in $\mathrm{Mg}^{2+}$. The inhibition data showed that $\alpha \mathrm{V} \beta 3-\mathrm{FN}$ complexes formed in $\mathrm{Mg}^{2+}$ could not be dissociated by RGD-based peptides (Figure 6A, B), whereas complexes formed in $\mathrm{Ca}^{2+}$ were weakly susceptible to dissociation by these reagents (Figure 6D, E). The dissociation rate of $\alpha \mathrm{V} \beta 3-\mathrm{FN} / \mathrm{Ca}^{2+}$ complexes in the presence of cilengitide or cRGD was 
3 -fold higher than in the absence of peptide (Figure 6 legend). EDTA still had only a very small effect on the dissociation rate in either $\mathrm{Mg}^{2+}$ or $\mathrm{Ca}^{2+}$ (Figure 6C, F).

\section{Integrin-FN complexes can be dissociated by $\mathrm{Ca}^{2+}$}

Because $\mathrm{Ca}^{2+}$ was able to influence whether RGD-based inhibitors could dissociate $\alpha \mathrm{V} \beta 3-\mathrm{FN}$ complexes, we next tested if $\mathrm{Ca}^{2+}$ itself could affect the dissociation of integrin-FN complexes formed in the presence of $\mathrm{Mn}^{2+} . \mathrm{Ca}^{2+}$ was added during the dissociation phase at a concentration of $2 \mathrm{mM}$ in running buffer without $\mathrm{Mn}^{2+}$. To our surprise, we found that $\mathrm{Ca}^{2+}$ was highly effective at dissociating $\alpha \mathrm{V} \beta 3-\mathrm{FN}$ complexes (Figure 7A), with the dissociation rate of $\alpha \mathrm{V} \beta 3-\mathrm{FN}$ complexes in the presence of $\mathrm{Ca}^{2+}$ being $>50$-fold higher than that in running buffer alone (Figure 7 legend), or that in running buffer with no bivalent cations (not shown). $\mathrm{Ca}^{2+}$ was also very effective at dissociating other integrin-FN complexes (Figure 7B-D). In contrast, addition of buffer with $5 \mathrm{mM} \mathrm{Mg}{ }^{2+}$ had little or no effect on the dissociation rate (Figure 7A-D).

To assess the concentration of $\mathrm{Ca}^{2+}$ required to give half-maximal inhibition, and thereby to estimate the apparent affinity of $\mathrm{Ca}^{2+}$ binding, we measured the dissociation rate of $\alpha \mathrm{V} \beta 3-\mathrm{FN}$ complexes at varying concentrations of $\mathrm{Ca}^{2+}$ and plotted the dissociation rate versus $\left[\mathrm{Ca}^{2+}\right]$ (Figure 7E, F). The results (Figure 7 legend) suggest that $\mathrm{Ca}^{2+}$ acts through a site of moderate affinity (apparent $\mathrm{K}_{\mathrm{D}} \sim 0.4 \mathrm{mM}$ ). Similar results were obtained for $\alpha 5 \beta 1$ (Supplementary Figure S2), although because of a marked increase in the dissociation rate of $\alpha 5 \beta 1-\mathrm{FN}$ complexes in the absence of $\mathrm{Mn}^{2+}$ (probably due to gradual loss of the MIDAS cation), it was not feasible to accurately fit the data to obtain an apparent $K_{D}$ value for these complexes.

\section{Blockade of the effect of $\mathrm{Ca}^{2+}$ by $\mathrm{Mn}^{2+}$ but not $\mathrm{Mg}^{2+}$}

We next investigated whether it was possible to overcome the effect of $\mathrm{Ca}^{2+}$ by co-addition of $\mathrm{Mn}^{2+}$ or $\mathrm{Mg}^{2+}$ during the dissociation phase. For these experiments we used a constant concentration of $\mathrm{Ca}^{2+}(0.2 \mathrm{mM})$, alone or in combination with $1 \mathrm{mM} \mathrm{Mn}^{2+}$ or $5 \mathrm{mM} \mathrm{Mg}^{2+}$. Both $\alpha \mathrm{V} \beta 3-\mathrm{FN}$ and $\alpha 5 \beta 1-\mathrm{FN}$ complexes were tested. The results (Figure $8 \mathrm{~A}, \mathrm{~B}$ ) showed that $\mathrm{Mn}^{2+}$ but not $\mathrm{Mg}^{2+}$ is able to abrogate the effect of $\mathrm{Ca}^{2+}$ on the dissociation rate. To assess the concentration of $\mathrm{Mn}^{2+}$ required to achieve $50 \%$ recovery of the dissociation rate in $\mathrm{Mn}^{2+}$ alone, we added varying concentrations of $\mathrm{Mn}^{2+}$ with $0.2 \mathrm{mM} \mathrm{Ca}^{2+}$ (Figure $8 \mathrm{C}, \mathrm{D}$ ). We then fitted the dissociation rate versus $\left[\mathrm{Mn}^{2+}\right]$ to obtain an 'IC50' value (the concentration of $\mathrm{Mn}^{2+}$ at which the effect of $\mathrm{Ca}^{2+}$ is $50 \%$ inhibited; fitting not shown). Results for $\alpha \mathrm{V} \beta 3-\mathrm{FN}$ complexes were $\sim 0.1 \mathrm{mM}$ (see Figure 8 legend). Similar results were obtained for $\alpha 5 \beta 1-\mathrm{FN}$ complexes (Figure 8 legend), although for these complexes the ability of $\mathrm{Mn}^{2+}$ to replace the gradually lost MIDAS ion may contribute to recovery of the dissociation rate. Higher concentrations of $\mathrm{Ca}^{2+}$ required higher concentrations of $\mathrm{Mn}^{2+}$ to block their effects (data not shown). The simplest explanation for these data are that $\mathrm{Mn}^{2+}$ and $\mathrm{Ca}^{2+}$ are able to compete for binding to the same site on the integrin; this site cannot bind $\mathrm{Mg}^{2+}$ but does bind either $\mathrm{Mn}^{2+}$ or $\mathrm{Ca}^{2+}$ with similar moderate affinity.

\section{A stimulatory $\mathrm{mAb}$ directed against the $\beta$ subunit is able to overcome the effect of $\mathrm{Ca}^{2+}$, whereas an inhibitory $\mathbf{m A b}$ mimics its effect}

We postulated that $\mathrm{Ca}^{2+}$ may have an allosteric effect on integrin-FN complexes because $\mathrm{Ca}^{2+}$ is known to have inhibitory effects on $\mathrm{Mn}^{2+}$-supported ligand binding by favouring the 
closed form of the $\beta \mathrm{I}$ domain $[13,20]$. We therefore hypothesised that a $\mathrm{mAb}$ whose binding favours the open form of $\beta$ I may be able to overcome the ability of $\mathrm{Ca}^{2+}$ to dissociate integrin-FN complexes. For this experiment we used the stimulatory mAb TS2/16, which binds in the $\alpha 2$ helix region of the $\beta 1$ subunit $\beta \mathrm{I}$ domain [39]. Binding of $\alpha 5 \beta 1$ to $50 \mathrm{~K}$ took place for $120 \mathrm{~s}$ in the absence or presence of a Fab fragment of TS2/16. A Fab fragment of $\mathrm{N} 29$, a mAb that binds to the $\beta 1$ subunit PSI domain [12], was used as a control. After a $60 \mathrm{~s}$ dissociation period the $\alpha 5 \beta 1-\mathrm{FN}$ or $\alpha 5 \beta 1-\mathrm{Fab}-\mathrm{FN}$ complexes were challenged with buffer containing $1 \mathrm{mM} \mathrm{Mn}^{2+}$, or buffer containing $0.2 \mathrm{mM} \mathrm{Ca}^{2+}$. The results showed that $\mathrm{TS} 2 / 16$, but not N29, was able to greatly reduce the ability of $\mathrm{Ca}^{2+}$ to dissociate the complexes (Figure 9A and Figure 9 legend).

Conversely, we also hypothesised that an antibody that has the opposite effect of TS2/16 may be able to mimic the effect of $\mathrm{Ca}^{2+}$. For this experiment we used a function-blocking mAb 13 , an allosteric inhibitor of $\beta 1$ integrins that, like TS2/16, binds in the $\alpha 2$ helix region of the $\beta I$ domain $[39,40]$. mAb 13 was added during the dissociation phase of $\alpha 5 \beta 1-\mathrm{FN}$ complexes in the presence of $\mathrm{Mn}^{2+}$. We found that $\mathrm{mAb} 13$ was able to increase the dissociation rate of these complexes $\sim 10$-fold, i.e., to a similar extent as $0.2 \mathrm{mM} \mathrm{Ca}^{2+}$ (Figure 9B and legend). A control anti- $\beta 1 \mathrm{mAb}, 8 \mathrm{E} 3$, did not increase the dissociation rate, whereas a second inhibitory $\mathrm{mAb}, 4 \mathrm{~B} 4$, did increase the dissociation rate but to a lesser extent than 13 (Supplementary Figure S3). 


\section{DISCUSSION}

Our major findings are: (i) non-reversibility of integrin-FN complexes by RGD-based peptides is a common feature of RGD-binding integrins, (ii) the non-reversible state forms very rapidly, and the time-dependent formation of a tightly bound state is not necessary for non-reversibility, (iii) $\alpha \mathrm{V} \beta 3-\mathrm{FN}$ complexes cannot be disrupted by EDTA, although those of other RGD-binding integrins are readily dissociated, (iv) the non-reversible state is dependent on regions within the integrin headpiece: the legs are not required, $(\mathrm{v}) \mathrm{Ca}^{2+}$ can rapidly disrupt integrin-FN complexes, even for $\alpha \mathrm{V} \beta 3$, (vi) $\mathrm{Ca}^{2+}$ acts through a site that also binds $\mathrm{Mn}^{2+}$ but not $\mathrm{Mg}^{2+}$, and (vii) the effect of $\mathrm{Ca}^{2+}$ can be overcome by locking the $\beta \mathrm{I}$ domain in an open state, whereas promoting the closed state of $\beta \mathrm{I}$ has a similar effect to $\mathrm{Ca}^{2+}$ binding. Taken together, our data demonstrate that integrin-FN complexes can be dissociated by allosteric inhibitors but not by competitive (ligand-mimetic) inhibitors.

\section{The non-reversible and time-stabilised states}

The inability of small peptides to disrupt the preformed integrin-FN complex indicates that the ligand-binding pocket, which includes the MIDAS site, is not accessible to these peptides in the ligand-bound state of the integrin. Shielding of ligand-binding pocket residues by ligand masking has been noted in other systems [41,42]. For $\alpha 5 \beta 1, \alpha \mathrm{V} \beta 1$ and $\alpha \mathrm{V} \beta 6$ complexes the MIDAS site is still accessible to chelators such as EDTA, but it appears that this is not the case for $\alpha \mathrm{V} \beta 3$ complexes. EDTA-insensitive binding of $\alpha \operatorname{IIb} \beta 3$ to fibrinogen has also been reported [43], suggesting that in $\beta 3$ complexes the MIDAS cation may be tightly shielded by ligand and integrin amino acid side-chains. There is crystallographic evidence for burial of the MIDAS cation in ligand-bound (although closed) forms of $\alpha \operatorname{IIb} \beta 3$ and $\alpha 5 \beta 1[44,19]$.

We showed that non-reversibility is a feature of both high and low affinity states of the integrin, and therefore this property seems not to be dependent upon opening of the headpiece. However, local conformational changes supported by $\mathrm{Mn}^{2+}$ or $\mathrm{Mg}^{2+}$ but not by $\mathrm{Ca}^{2+}$ appear to be required for binding to become non-reversible for $\alpha \mathrm{V} \beta 3$. It is likely that these changes take place within the vicinity of the ligand-binding pocket itself [16], and probably involve movement of the $\alpha 1$ helix of the $\beta$ I domain (see below). The time-stabilised state we observed (with very low $k_{d}$ ) is likely to have the open headpiece [13] and be tightly held in this conformation. In support of this proposal, states with very low dissociation rates can also be formed using mAbs that 'lock' in the integrin in the open state [26, see also Figure 9A]. It is currently unclear how such long-lived states relate to those caused by mechanical reinforcement [45-47].

\section{Nature of the $\mathrm{Ca}^{2+}$-binding inhibitory site and mechanism of function-altering $\mathrm{mAbs}$}

Our results indicated that $\mathrm{Ca}^{2+}$ exerted its effects on the integrin-FN complex through binding a site that could be occupied by $\mathrm{Ca}^{2+}$ or $\mathrm{Mn}^{2+}$ but not by $\mathrm{Mg}^{2+}$. This site is clearly not the MIDAS since $\mathrm{Mg}^{2+}$ can bind there. Furthermore, this site must be distinct from the MIDAS because $\mathrm{Ca}^{2+}$ would be unable to displace the tightly bound MIDAS $\mathrm{Mn}^{2+}$ ion from $\alpha V \beta 3$. Another possibility is the SyMBS, which binds $\mathrm{Ca}^{2+}$ with high affinity (apparent $\mathrm{K}_{\mathrm{D}}$ $<0.1 \mathrm{mM}$ ) but can also bind $\mathrm{Mn}^{2+}[21,23,25]$. However, we strongly favour the idea that this site is the ADMIDAS because (i) the ADMIDAS binds $\mathrm{Ca}^{2+}$ with moderate affinity $[23,26]$ (apparent $K_{D}>0.1 \mathrm{mM}$ ), akin to what is observed here, (ii) the ADMIDAS does not bind $\mathrm{Mg}^{2+}$ [51], (iii) $\mathrm{Ca}^{2+}$ is known to act as an inhibitor of $\mathrm{Mn}^{2+}$-supported ligand binding by 
binding to the ADMIDAS [23,26], (iv) occupancy of the ADMIDAS by $\mathrm{Ca}^{2+}$ causes conformational shifts in the $\beta$ I domain that favour the closed form of the headpiece $[13,24]$, (v) $\mathrm{Mn}^{2+}$ can compete with $\mathrm{Ca}^{2+}$ for binding to the ADMIDAS [16,23,48], (vi) stimulatory antibodies or activating mutations, that favour the open form of the headpiece can overcome the inhibitory effects of ADMIDAS site mutations in $\beta 1$ and $\beta 3$ integrins [24,26,49]. Additionally, the SyMBS may not be accessible to $\mathrm{Ca}^{2+}$ in the integrin-ligand complex because it, like the MIDAS, can become deeply buried [19]. In contrast, the ADMIDAS is not directly involved in interaction with the ligand and is unlikely to become buried. Our findings, and previous studies [16,23], suggest that the action of $\mathrm{Ca}^{2+}$ at the ADMIDAS is outside of the ligand-binding pocket, i.e. it acts allosterically.

The ADMIDAS site is linked to the top of the $\alpha 1$ helix via coordinating residues in the loop between $\beta$-strand 1 and $\alpha 1$ ( $\beta 1-\alpha 1$ loop). In the transition from the open to closed forms of the $\beta I$ domain there is a major movement of the ADMIDAS ion, $\beta 1-\alpha 1$ loop and $\alpha 1$ helix towards the $\alpha$ subunit [16]. The inward motion of the $\alpha 1$ helix eventually leads to loss of coordination of the ADMIDAS cation by the backbone carbonyl of Met 335 ( $\beta 3$ sequence), which then frees the $\alpha 7$ helix to undergo a downward piston-like motion that propels the outward swing of the hybrid domain [16]. It has been proposed [23] that since $\mathrm{Ca}^{2+}$, but not $\mathrm{Mn}^{2+}$, has a strong inclination to coordinate carbonyl groups [50], binding of $\mathrm{Ca}^{2+}$ at the ADMIDAS site favours the closed state, whereas occupancy of the ADMIDAS site by $\mathrm{Mn}^{2+}$ favours the open state. Stimulatory (e.g. TS2/16) and function-blocking anti- $\beta 1 \mathrm{mAbs}$ (e.g. 13 and 4B4) bind in the $\alpha 2$ helix region of the $\beta I$ domain, and appear to regulate integrin activity by affecting the position of the adjacent $\alpha 1$ helix $[12,19]$. Importantly, inhibitory anti- $\beta 1 \mathrm{mAbs}$ and occupancy of the ADMIDAS site by $\mathrm{Ca}^{2+}$ appear to perturb ligand binding in a very similar manner, i.e, by favouring the position of the $\alpha 1$ helix found in the closed state. On the other hand, the binding of stimulatory mAbs favours the position of the $\alpha 1$ helix found in the open state [12], and hence binding of these mAbs could overcome the effect of $\mathrm{Ca}^{2+}$ occupancy of the ADMIDAS.

\section{Future applications for drug development}

To identify novel allosteric inhibitors of integrins, the SPR system described here could be utilised in the future for medium throughput screening of small-molecule libraries: five compounds can be screened simultaneously in less than ten minutes. It could also be used for further analysis of allosteric antagonists to measure the maximal effect on the dissociation rate, and the concentration for half-maximal effect (as described here for $\mathrm{Ca}^{2+}$ ).

RGD-based integrin antagonists, such as cilengitide, have had very limited success in the clinic for the treatment of cancer [51,52]. Our data suggest this lack of efficacy could be due to the inability of such compounds to disrupt pre-existing integrin-ligand interactions, although other explanations are possible [53]. Several types of allosteric inhibitors for integrins have previously been described [44,54-56], although their effects on preformed integrin-ligand complexes have not yet been reported. Allosteric antagonists that can mimic the effect of $\mathrm{Ca}^{2+}$ (i.e., promote the closed form of the headpiece) have the potential not only to prevent new integrin adhesions forming but also to dissociate pre-formed adhesions. Hence, we propose that the use of such inhibitors may prove of greater clinical benefit than ligand-mimetic antagonists.

Additionally, allosteric antagonists could have two further advantages over competitive antagonists. First, the oral bioavailability of RGD-based antagonists has been restricted by the 
essential requirement to include a carboxylic acid moiety [57,58]. Allosteric antagonists would not have this limitation, and could therefore have improved pharmacokinetic properties. Second, allosteric antagonists are likely to have a much lower risk of thrombotic or thrombocytopenic side-effects $[3,59,60]$. Allosteric inhibitors could also be powerful adjuvants to existing integrin therapies. 


\section{AUTHOR CONTRIBUTION}

Paul Mould performed the experiments, designed the project and wrote the manuscript. Sarah Byron and Susan Craig prepared integrins $\alpha \mathrm{V} \beta 1$ and $\alpha \mathrm{V} \beta 6$ and Fab fragments. Thomas Jowitt helped with experimental design, and Martin Humphries and other authors contributed to manuscript preparation/revision.

\section{ACKNOWLEDGEMENTS}

We thank J. Popplewell and T. Springer for helpful discussions, J. Humphries for comments on the manuscript, $S$. Goodman for recombinant $\alpha V \beta 3$, D. Cheresh for cilengitide, $S$. Ludbrook for integrin constructs, and J. Wilkins, F. Sánchez-Madrid and K. Yamada for antibodies. We are grateful to M. Howard for assistance with purification and analysis of recombinant integrins and fibronectin fragments, and A. Byron for LC-MS/MS analyses. This work was supported by a studentship from the Biotechnology and Biological Sciences Research Council and GlaxoSmithKline (to SKB) and grants from the Wellcome Trust (to MJH). 


\section{References}

1. Hynes, R. O. (2002) Integrins: bidirectional, allosteric signalling machines. Cell 110, 673-687

2. Goodman, S. L. and Picard, M. (2012) Integrins as therapeutic targets. Trends Pharmacol. Sci. 33, 405-412

3. Cox, D., Brennan, M.and Moran, N. (2010) Integrins as therapeutic targets: lessons and opportunities. Nat. Rev. Drug Discov. 9, 804-820

4. Reardon, D. A. and Cheresh, D. (2011) Cilengitide: a prototypic integrin inhibitor for the treatment of glioblastoma and other malignancies. Genes Cancer 2, 1159-1165

5. Sheldrake, H. M. and Patterson, L. H. (2014). Strategies To Inhibit Tumor Associated Integrin Receptors: Rationale for Dual and Multi-Antagonists. J. Med. Chem. 57, 63016315

6. Xiong, J. P., Stehle, T., Diefenbach, B., Zhang, R., Dunker, R., Scott, D. L., Joachimiak, A., Goodman, S. L. and Arnaout, M. A. (2001) Crystal structure of the extracellular segment of integrin $\alpha \mathrm{V} \beta 3$. Science 294, 339-345

7. Xiao, T., Takagi, J., Coller, B. S., Wang, J. H. and Springer, T. A. (2004). Structural basis for allostery in integrins and binding to fibrinogen-mimetic therapeutics. Nature 432, 59-67

8. Luo, B. H., Carman, C. V. and Springer, T. A. (2007) Structural basis of integrin regulation and signaling. Annu. Rev. Immunol. 25, 619-647

9. Kamata, T., Handa, M., Ito, S., Sato, Y., Ohtani, T., Kawai, Y., Ikeda, Y. and Aiso, S. (2010) Structural requirements for activation in $\alpha \operatorname{IIb} \beta 3$ integrin. J. Biol. Chem. 285, 38428-38437

10. Mould, A. P., Travis, M. A., Barton, S. J., Hamilton, J. A., Askari, J. A., Craig, S. E., Macdonald, P. R., Kammerer, R. A, Buckley, P. A and Humphries, M. J. (2005) Evidence that monoclonal antibodies directed against the integrin $\beta$ subunit plexin/semaphorin/integrin domain stimulate function by inducing receptor extension. $\mathrm{J}$. Biol. Chem. 280, 4238-4246

11. Askari, J. A., Buckley, P. A., Mould, A. P. and Humphries, M. J. (2009) Linking integrin conformation to function. J. Cell Sci. 122, 165-170

12. Mould, A. P., Askari, J. A., Barton, S., Kline, A. D., McEwan, P. A., Craig, S. E. and Humphries, M. J. (2002) Integrin activation involves a conformational change in the $\alpha 1$ helix of the $\beta$ subunit A-domain. J. Biol. Chem. 277, 19800-19806

13. Mould, A. P., Barton, S. J., Askari, J. A., McEwan, P. A., Buckley, P. A., Craig, S. E. and Humphries, M. J. (2003) Conformational changes in the integrin $\beta$ A domain provide a mechanism for signal transduction via hybrid domain movement. J. Biol. Chem. 278, 17028-17035

14. Barton, S. J., Travis, M. A., Askari, J. A., Buckley, P. A., Craig, S. E., Humphries, M. J. and Mould, A. P. (2004) Novel activating and inactivating mutations in the integrin $\beta 1$ subunit A domain. Biochem. J. 380, 401-407

15. Zhang, C., Liu, J., Jiang, X., Haydar, N., Zhang, C., Shan, H. and Zhu, J. (2013)

Modulation of integrin activation and signaling by $\alpha 1 / \alpha 1$ '-helix unbending at the junction.

J. Cell Sci. 126, 5735-5747

16. Zhu, J., Zhu, J. and Springer, T. A. (2013) Complete integrin headpiece opening in eight steps. J. Cell Biol. 201, 1053-1068

17. Xiong, J.-P., Stehle, T., Zhang, R., Joachimiak, A., Frech, M., Goodman, S. and Arnaout, M. A. (2002) Crystal structure of the extracellular segment of integrin $\alpha \mathrm{V} \beta 3$ in complex with an Arg-Gly-Asp ligand. Science (Washington, D.C.) 296, 151-155 
18. Mould, A. P., Koper, E. J., Byron, A., Zahn, G. and Humphries, M. J. (2009)

Mapping the ligand-binding pocket of integrin $\alpha 5 \beta 1$ using a gain-of-function approach. Biochem. J. 424, 179-189

19. Nagae M., Re S., Mihara, E., Nogi, T., Sugita, Y. and Takagi, J. (2012) Crystal structure of $\alpha 5 \beta 1$ integrin ectodomain: atomic details of the fibronectin receptor. J. Cell Biol. 197, 131-140

20. Zhu, J., Luo, B. H., Xiao, T., Zhang, C., Nishida, N. and Springer, T. A. (2008)

Structure of a complete integrin ectodomain in a physiologic resting state and activation and deactivation by applied forces. Mol. Cell. 32, 849-861

21. Mould, A. P., Akiyama, S. K. and Humphries, M. J. (1995) Regulation of integrin $\alpha 5 \beta 1$-fibronectin interactions by divalent cations. Evidence for distinct classes of binding sites for $\mathrm{Mn}^{2+}, \mathrm{Mg}^{2+}$, and $\mathrm{Ca}^{2+}$. J. Biol. Chem. 270, 26270-26277

22. Labadia, M. E., Jeanfavre, D. D., Caviness, G. O. and Morelock, M. M. (1998)

Molecular regulation of the interaction between leukocyte function-associated antigen-1 and soluble ICAM-1 by divalent metal cations. J. Immunol. 161, 836-842

23. Chen, J., Salas, A. and Springer, T. A. (2003) Bistable regulation of integrin adhesiveness by a bipolar metal ion cluster. Nat. Struct. Biol. 10, 995-1001

24. Chen, J., Takagi, J., Xie, C., Xiao, T., Luo, B. H. and Springer, T. A. (2004) The relative influence of metal ion binding sites in the I-like domain and the interface with the hybrid domain on rolling and firm adhesion by integrin $\alpha 4 \beta 7$. J. Biol. Chem. 279, 5555655561

25. Valdramidou, D., Humphries, M. J. and Mould, A. P. (2008) Distinct roles of $\beta 1$ metal ion-dependent adhesion site (MIDAS), adjacent to MIDAS (ADMIDAS), and ligand-associated metal-binding site (LIMBS) cation-binding sites in ligand recognition by integrin $\alpha 2 \beta 1$. J. Biol. Chem. 283, 32704-32714

26. Mould, A. P., Barton, S. J., Askari, J. A., Craig, S. E. and Humphries, M. J. (2003) Role of ADMIDAS cation-binding site in ligand recognition by integrin $\alpha 5 \beta 1$. J. Biol. Chem. 278, 51662-51629

27. Weikl, T. R. and von Deuster, C. (2009) Selected-fit versus induced-fit protein binding: kinetic differences and mutational analysis. Proteins 75, 104-110

28. Orlando, R. A. and Cheresh, D. A. (1991) Arginine-glycine-aspartic acid binding leading to molecular stabilization between integrin $\alpha v \beta 3$ and its ligand. J. Biol.

Chem. 266, 19543-19550

29. Kumar, C. C., Nie, H., Rogers, C. P., Malkowski, M., Maxwell, E., Catino, J. J. and Armstrong L. (1997) Biochemical characterization of the binding of echistatin to integrin $\alpha v \beta 3$ receptor. J. Pharmacol. Exp. Ther. 283, 843-853

30. Müller, B., Zerwes, H. G., Tangemann, K., Peter, J. and Engel, J. (1993) Two-step binding mechanism of fibrinogen to $\alpha \operatorname{IIb} \beta 3$ integrin reconstituted into planar lipid bilayers. J Biol Chem. 268, 6800-6808

31. Szabo, A. M., Howell, N. R., Pellegrini, P., Greguric, I. and Katsifis, A. (2012)

Development and validation of competition binding assays for affinity to the extracellular matrix receptors, $\alpha v \beta 3$ and $\alpha \mathrm{IIb} \beta 3$ integrin. Anal. Biochem. 423, 70-77

32. Coe, A. P. F., Askari, J. A., Kline, A. D., Robinson, M. K., Kirby, H., Stephens, P. E. and Humphries, M. J. (2001) Generation of a minimal $\alpha 5 \beta 1$ integrin-Fc fragment. J. Biol. Chem. 276, 35854-35866

33. Baggaley, S. K. (2007) Ligand-binding specificity of the integrin $\alpha$ V family. Ph. D. Thesis, University of Manchester.

34. Mould A. P., Garratt, A. N., Puzon-McLaughlin, W., Takada, Y. and Humphries, M.

J. (1998) Regulation of integrin function: evidence that bivalent-cation-induced 
conformational changes lead to the unmasking of ligand-binding sites within integrin $\alpha 5 \beta 1$. Biochem. J. 331, 821-828

35. Mould, A. P., Askari, J. A., Aota, S., Yamada, K. M., Irie, A., Takada, Y., Mardon, H. J. and Humphries, M. J. (1997) Defining the topology of integrin $\alpha 5 \beta 1$-fibronectin interactions using inhibitory anti- $\alpha 5$ and anti- $\beta 1$ monoclonal antibodies - Evidence that the synergy sequence of fibronectin is recognized by the amino-terminal repeats of the $\alpha 5$ subunit. J. Biol. Chem. 272, 17283-17292

36. Malmqvist M and Karlsson R. (1997) Biomolecular interaction analysis: affinity biosensor technologies for functional analysis of proteins. Curr. Opin. Chem. Biol. 1, 378383

37. Bravman, T., Bronner, V., Lavie, K, Notcovich, A, Papalia, G. A. and Myszka, D. G. (2006) Exploring "one-shot" kinetics and small molecule analysis using

the ProteOn XPR36 array biosensor. Anal. Biochem. 358, 281-288

38. Nahshol, O., Bronner, V., Notcovich, A., Rubrecht, L., Laune, D. and Bravman, T. Parallel kinetic analysis and affinity determination of hundreds of monoclonal antibodies using the ProteOn XPR36. (2008) Anal. Biochem. 383, 52-60

39. Takada, Y. and Puzon, W. (1993) Identification of a regulatory region of integrin $\beta 1$ subunit using activating and inhibiting antibodies. J. Biol. Chem. 268, 17597-17601 40. Mould, A. P., Akiyama, S. K. and Humphries, M. J. (1996) The inhibitory anti- $\beta 1$ integrin monoclonal antibody 13 recognizes an epitope that is attenuated by ligand occupancy. Evidence for allosteric inhibition of integrin function. J. Biol. Chem. 271, 20365-20374

41. Kisiela, D. I., Rodriguez, V. B., Tchesnokova, V., Avagyan, H., Aprikian, P., Liu, Y., Wu, X. R., Thomas, W. E. and Sokurenko, E. V. (2013) Conformational inactivation induces immunogenicity of the receptor-binding pocket of a bacterial adhesin. Proc. Natl. Acad. Sci. U S A 110, 19089-19094

42. Andersen, C. B., Torvund-Jensen, M., Nielsen, M. J., de Oliveira, C. L., Hersleth, H. P., Andersen, N. H., Pedersen, J. S., Andersen, G. R. and Moestrup, S. K. (2012)

Structure of the haptoglobin-haemoglobin complex. Nature 489, 456-459

43. Peerschke, E. I. B. (1999) Maintenance of GPIIb-IIIa avidity supporting "irreversible" fibrinogen binding is energy-dependent. J. Lab. Clin. Med. 134, 398-404

44. Zhu, J., Zhu, J., Negri, A., Provasi, D., Filizola, M., Coller, B. S. and Springer, T. A. (2010) Closed headpiece of integrin $\alpha \operatorname{IIb} \beta 3$ and its complex with an $\alpha \operatorname{IIb} \beta 3$-specific antagonist that does not induce opening. Blood 116, 5050-5059

45. Kong, F., García, A. J., Mould, A. P., Humphries, M. J. and Zhu, C. Demonstration of catch bonds between an integrin and its ligand. (2009) J. Cell Biol. 185, 1275-1284

46. Kong, F., Li, Z., Parks, W. M., Dumbauld, D. W., García, A. J., Mould, A. P., Humphries M. J. and Zhu, C. (2013) Cyclic mechanical reinforcement of integrin-ligand interactions. Mol. Cell 49, 1060-1068

47. Chakrabarti, S., Hinczewski, M. and Thirumalai, D. (2014) Plasticity of hydrogen bond networks regulates mechanochemistry of cell adhesion complexes. Proc. Natl. Acad.

Sci. U S A. doi: 10.1073/pnas.1405384111

48. Pesho, M. M., Bledzka, K., Michalec, L., Cierniewski, C. S. and Plow, E. F. (2006).

The specificity and function of the metal-binding sites in the integrin $\beta 3 \mathrm{~A}$-domain. J.

Biol. Chem. 281, 23034-23041

49. Raborn, J., Wang W. and Luo, B.-H. (2012) Regulation of integrin $\alpha \operatorname{IIb} \beta 3$ ligand binding and signaling by the metal ion binding sites in the $\beta$ I domain. J. Cell. Biochem.

113, 1190-1197

50. Harding, M. M. (2001) Geometry of metal-ligand interactions in proteins. Acta Crystallogr. D 57, 401-411 
51. Stupp, R., Hegi, M. E., Gorlia, T., Erridge, S. C., Perry, J., Hong, Y. K., Aldape, K. D., Lhermitte, B., Pietsch, T., Grujicic, D., Steinbach, J. P., Wick, W., Tarnawski, R., Nam, D. H., Hau, P., Weyerbrock, A., Taphoorn, M. J., Shen, C. C., Rao, N., Thurzo, L., Herrlinger, U., Gupta, T., Kortmann, R. D., Adamska, K., McBain, C., Brandes, A. A., Tonn, J. C., Schnell, O., Wiegel, T., Kim, C. Y., Nabors, L. B., Reardon, D. A., van den Bent M. J., Hicking, C., Markivskyy, A., Picard M. and Weller, M. (2014) Cilengitide combined with standard treatment for patients with newly diagnosed glioblastoma with methylated MGMT promoter (CENTRIC EORTC 26071-22072 study): a multicentre, randomised, open-label, phase 3 trial. Lancet Oncol. 15, 1100-1108

52. Soffietti, R., Trevisan, E., and Rudà, R. (2014) What have we learned from trials on antiangiogenic agents in glioblastoma? Expert Rev. Neurother. 14, 1-3

53. Robinson S. D and Hodivala-Dilke, K. M. (2011) The role of $\beta 3$-integrins in tumor angiogenesis: context is everything. Curr. Opin. Cell Biol. 23, 630-637

54. Shimaoka, M. and Springer, T. A. (2003) Therapeutic antagonists and conformational regulation of integrin function. Nat. Rev. Drug Disc. 2, 703-716

55. Ghitti, M., Spitaleri, A., Valentinis, B., Mari, S., Asperti, C., Traversari, C., Rizzardi, G. P. and Musco, G. (2012) Molecular dynamics reveal that isoDGR-containing cyclopeptides are true $\alpha \mathrm{v} \beta 3$ antagonists unable to promote integrin allostery and activation. Angew Chem. Int. Ed. Engl. 51, 7702-7705

56. Kapp, T. G., Rechenmacher, F., Sobahi, T. R. and Kessler, H. (2013). Integrin modulators: a patent review. Expert. Opin. Ther. Pat. 23, 1273-1295

57. Khojasteh, S. C., Leipold, D. D., Lai, F., La, H., Baumgardner, M. J., Desino, K. E., Halland, N., Blum, H., Buning, C., Kohlmann M. and Lindenschmidt, A. (2014) Small Macrocycles As Highly Active Integrin $\alpha 2 \beta 1$ Antagonists. ACS Med. Chem. Lett. 5, 193198

58. Gudmundsson, O. S., Bloedow, D. C., Bodary, S. C., Reynolds, M. E., Gadek, T. R. and Kenkare-Mitra S. (2008) Preclinical absorption, distribution, metabolism and excretion (ADME) characterization of ICAM1988, an LFA-1/ICAM antagonist, and its prodrug. Xenobiotica. 38, 340-352

59. Gao, C., Boylan, B., Bougie, D., Gill, J. C., Birenbaum, J., Newman, D. K., Aster, R. H. and Newman, P. J. (2009) Eptifibatide-induced thrombocytopenia and thrombosis in humans require FcgammaRIIa and the integrin $\beta 3$ cytoplasmic domain. J. Clin. Invest. 119, 504-511

60. Mahalingam, B., Van Agthoven. J. F., Xiong, J. P., Alonso, J. L., Adair, B. D., Rui, X., Anand, S., Mehrbod, M., Mofrad, M. R., Burger, C., Goodman S. L and Arnaout, M. A. (2014) Atomic basis for the species-specific inhibition of $\alpha \mathrm{V}$ integrins by mAb 17E6 is revealed by the crystal structure of $\alpha \mathrm{V} \beta 3$ ectodomain-17E6 Fab complex. J. Biol. Chem. 289, 13801-13809 


\section{FIGURE LEGENDS}

\section{Figure 1. Binding kinetics of integrins to $50 \mathrm{~K}$ fibronectin fragment.}

Binding of $\alpha 5 \beta 1-\mathrm{Fc}(\mathrm{A}), \alpha \mathrm{V} \beta 1$ (B), $\alpha \mathrm{V} \beta 3$ (C), or $\alpha \mathrm{V} \beta 6$ (D) took place for $180 \mathrm{~s}$ (or $120 \mathrm{~s}$ for $\alpha \mathrm{V} \beta 1$ and $\alpha \mathrm{V} \beta 6)$ in six parallel channels in RBMn, followed by dissociation (1800 -2400 s) in the same buffer. Concentrations of integrins used were 10, 6.67, 3.33, 1.67, 0.83, and 0.42 $\mathrm{nM}$ for $\alpha 5 \beta 1 ; 100,75,50,25,12.5$, and $6.3 \mathrm{nM}$ for $\alpha \mathrm{V} \beta 1$ and $\alpha \mathrm{V} \beta 6 ; 110,82.5,55,27.5,13.8$, and $6.9 \mathrm{nM}$ for $\alpha \mathrm{V} \beta 3$ (orange, magenta, green, blue, cyan and red sensorgrams, respectively)

\section{Figure 2. Kinetic analyses of binding of integrins to $50 \mathrm{~K}$}

Sensorgrams are as shown in Figure 1. Black lines show fitted curves (locally fitted $\mathrm{R}_{\max }$ ). AD Analysis of kinetics of $\alpha 5 \beta 1-\mathrm{Fc}(\mathrm{A}), \operatorname{rs} \alpha \mathrm{V} \beta 1$ (B), $\alpha \mathrm{V} \beta 3 \Delta \mathrm{TM}(\mathrm{C})$, or $\operatorname{rs} \alpha \mathrm{V} \beta 6$ (D) binding to $50 \mathrm{~K}$ using a heterogeneous analyte model. $\chi^{2}$ values were 1.11 for $\alpha 5 \beta 1,1.15$ for $\alpha \mathrm{V} \beta 1,1.18$ for $\alpha \mathrm{V} \beta 3,0.98$ for $\alpha \mathrm{V} \beta 6$. E-H Analysis of kinetics of $\alpha 5 \beta 1-\mathrm{Fc}(\mathrm{E}), \operatorname{rs} \alpha \mathrm{V} \beta 1$ (F), $\alpha \mathrm{V} \beta 3 \Delta \mathrm{TM}$ $(\mathrm{G})$, or $\operatorname{rs} \alpha \mathrm{V} \beta 6(\mathrm{H})$ binding to binding $50 \mathrm{~K}$ using a two-state model. $\chi^{2}$ values were 1.12 for $\alpha 5 \beta 1,1.15$ for $\alpha \mathrm{V} \beta 1,1.18$ for $\alpha \mathrm{V} \beta 3,0.94$ for $\alpha \mathrm{V} \beta 6$. I-L Analysis of kinetics of $\alpha 5 \beta 1-\mathrm{Fc}$ (I), $\operatorname{rs} \alpha \mathrm{V} \beta 1(\mathrm{~J}), \alpha \mathrm{V} \beta 3 \Delta \mathrm{TM}(\mathrm{K})$, or $\operatorname{rs} \alpha \mathrm{V} \beta 6(\mathrm{~L})$ binding to $50 \mathrm{~K}$ using a Langmuir 1:1 model. $\chi^{2}$ values were 6.08 for $\alpha 5 \beta 1,7.71$ for $\alpha \mathrm{V} \beta 1,5.95$ for $\alpha \mathrm{V} \beta 3,6.41$ for $\alpha \mathrm{V} \beta 6$.

\section{Figure 3. Effect of cilengitide and cRGD peptide on the dissociation of integrin-FN complexes.}

Binding of $\alpha 5 \beta 1-\mathrm{Fc}(\mathrm{A}, \mathrm{E}), \alpha \mathrm{V} \beta 1(\mathrm{~B}, \mathrm{~F}), \alpha \mathrm{V} \beta 3(\mathrm{C}, \mathrm{G})$, or $\alpha \mathrm{V} \beta 6(\mathrm{D}, \mathrm{H})$ to $50 \mathrm{~K}$ took place for $120 \mathrm{~s}$ in three parallel channels in RBMn, followed by RBMn injection for $60 \mathrm{~s}$. At the time indicated by the downward pointing arrow (approx. $207 \mathrm{~s}$ ) either RBMn alone (red sensorgrams) or RBMn with approx. $1 \mu \mathrm{M}$ cilengitide (cyan sensorgrams in panels A-D) or 1 $\mu \mathrm{M}$ cRGD (cyan sensorgrams in panels E-H) was injected for approx. $120 \mathrm{~s}$. No binding to $50 \mathrm{~K}$ was observed if $1 \mu \mathrm{M}$ cilengitide or cRGD was present during the association phase (blue sensorgrams).

\section{Figure 4. Effect of EDTA on the dissociation of integrin-FN complexes.}

Binding of $\alpha 5 \beta 1-\mathrm{Fc}(\mathrm{A}), \alpha \mathrm{V} \beta 1$ (B), $\alpha \mathrm{V} \beta 3$ (C), or $\alpha \mathrm{V} \beta 6$ (D) to $50 \mathrm{~K}$ was allowed to proceed for $120 \mathrm{~s}$ in three parallel channels in RBMn, followed by RBMn injection for $60 \mathrm{~s}$. At the time indicated by the downward pointing arrow (approx. $207 \mathrm{~s}$ ) either RBMn (red sensorgram) or RB0 with 5mM EDTA (cyan sensorgram) was injected for approx. $120 \mathrm{~s}$. No binding to $50 \mathrm{~K}$ was observed if EDTA was present during the association phase (blue sensorgram). In this experiment, the dissociation rate of $\alpha \mathrm{V} \beta 3$ in RBMn was $6.7 \times 10^{-4} \mathrm{~s}^{-1}$, the rate in RB0 with 5mM EDTA was $9.6 \times 10^{-4} \mathrm{~s}^{-1}$ (measured from 208-320 s).

Figure 5. Binding kinetics of a truncated $\alpha 5 \beta 1$ integrin to $50 \mathrm{~K}$, and effect of inhibitors on dissociation rate. 
A, Binding kinetics of TR $\alpha 5 \beta 1-\mathrm{Fc}$ to $50 \mathrm{~K}$. Binding took place for $180 \mathrm{~s}$ in six parallel channels in RBMn, followed by dissociation in the same buffer. Concentrations of integrin used were 24, 16, 8, 4, 2, and $1 \mathrm{nM}$ (orange, magenta, green, blue, cyan and red sensorgrams, respectively). B-D, Analysis of binding kinetics of TR $\alpha 5 \beta 1$-Fc. B, heterogeneous analyte model. C, two-state model. D, 1:1 model. Black lines show fitted curves (locally fitted $\mathrm{R}_{\max }$ ). $\chi^{2}$ values were 1.11 for heterogeneous analyte model, 1.12 for two-state model, and 12.19 for 1:1 model. E, Analysis of the effect of association time on dissociation kinetics. TR $\alpha 5 \beta 1-\mathrm{Fc}$ $(80 \mathrm{nM})$ binding to $50 \mathrm{~K}$ took place for $120 \mathrm{~s}$ (red sensorgram) $240 \mathrm{~s}$ (grey sensorgram) or $480 \mathrm{~s}$ (black sensorgram). The dissociation phase was then followed for $1800 \mathrm{~s}$. To aid comparison between sensorgrams, they are aligned at the start of the dissociation phase. F-H, binding of TR $\alpha 5 \beta 1-\mathrm{Fc}$ to $50 \mathrm{~K}$ took place for $120 \mathrm{~s}$ in three parallel channels in RBMn, followed by RBMn injection for $60 \mathrm{~s}$. At the time indicated by the downward pointing arrow (approx. $207 \mathrm{~s}$ ) either RBMn alone (red sensorgrams) or RBMn with $5 \mu \mathrm{M}$ cilengitide (cyan sensorgram panel F), or RBMn with $100 \mu \mathrm{M}$ cRGD (cyan sensorgram panel G), or RB0 with $2.5 \mathrm{mM}$ EDTA (cyan sensorgram panel $\mathrm{H}$ ) was injected for approx. $120 \mathrm{~s}$. No binding to $50 \mathrm{~K}$ was observed if inhibitors were present during the association phase (blue sensorgrams). Note the difference in time scales between panels A-E and panels F-H.

\section{Figure 6. Effect of $\mathrm{Mg}^{2+}$ and $\mathrm{Ca}^{2+}$ on the dissociation of $\alpha \mathrm{VB3}-\mathrm{FN}$ complexes by RGD- based antagonists or EDTA.}

Binding of $\alpha \mathrm{V} \beta 3$ to $50 \mathrm{~K}$ took place for $120 \mathrm{~s}$ in three parallel channels in RB0 containing 5 $\mathrm{mM} \mathrm{Mg}^{2+}$ (A-C), or RB0 containing $2 \mathrm{mM} \mathrm{Ca}^{2+}$ (D-F) followed by injection of the same running buffer for $60 \mathrm{~s}$. At the time indicated by the downward pointing arrow (approx. 207

s) either running buffer alone (red sensorgram) or running buffer with $1 \mu \mathrm{M}$ cilengitide (cyan sensorgram in panels A, D) or $2 \mu \mathrm{M}$ cRGD (cyan sensorgram in panels B, E), or RB0 with 5 mM EDTA (cyan sensorgram in panels C, F), was injected for approx. $120 \mathrm{~s}$. No binding to $50 \mathrm{~K}$ was observed if inhibitors were present during the association phase (blue sensorgrams). In panel $\mathrm{D}$, the dissociation rate of $\alpha \mathrm{V} \beta 3-\mathrm{FN}$ complexes in $\mathrm{Ca}^{2+}$ was $4.2 \times 10^{-3} \mathrm{~s}^{-1}$, the rate in the presence of cilengitide was $11.8 \times 10^{-3} \mathrm{~s}^{-1}$. In panel $\mathrm{E}$, the dissociation rate of $\alpha \mathrm{V} \beta 3-\mathrm{FN}$ complexes in $\mathrm{Ca}^{2+}$ was $3.7 \times 10^{-3} \mathrm{~s}^{-1}$, the rate in the presence of cRGD was $9.7 \times 10^{-3} \mathrm{~s}^{-1}$.

Figure 7. Effect of $\mathrm{Ca}^{2+}$ on the dissociation of integrin-FN complexes formed in $\mathrm{Mn}^{2+}$. Binding of $\alpha \mathrm{V} \beta 3$ (A), $\alpha \mathrm{V} \beta 1$ (B), $\alpha 5 \beta 1-\mathrm{Fc}(\mathrm{C})$, and $\alpha \mathrm{V} \beta 6$ (D) to $50 \mathrm{~K}$ took place for $120 \mathrm{~s}$ in three parallel channels in RBMn, followed by injection of the same buffer for $60 \mathrm{~s}$. At the time indicated by the downward pointing arrow (approx. $207 \mathrm{~s}$ ) either RBMn (red sensorgram), or RB0 with $2 \mathrm{mM} \mathrm{Ca}^{2+}$ (blue sensorgram), or RB0 with $5 \mathrm{mM} \mathrm{Mg}^{2+}$ (cyan sensorgram) was injected for approx. $120 \mathrm{~s}$. For $\alpha \mathrm{V} \beta 3$ the dissociation rate in RBMn was 6.7 $\times 10^{-4} \mathrm{~s}^{-1}$, dissociation rate in running buffer with $2 \mathrm{mM} \mathrm{Ca}^{2+}$ was $3.6 \times 10^{-2} \mathrm{~s}^{-1}$. Panel E shows an experiment in which binding of $\alpha \mathrm{V} \beta 3$ to $50 \mathrm{~K}$ took place for $120 \mathrm{~s}$ in six parallel channels, followed by buffer injection for $60 \mathrm{~s}$. At the time indicated by the downward

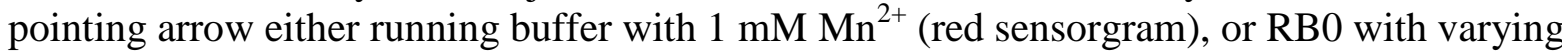
concentrations of $\mathrm{Ca}^{2+}$ (as indicated on the other sensorgrams), was injected for approx. 120 s. Panel F shows a hyperbolic fit of the dissociation rate from approx. 208-320 s plotted against $\left[\mathrm{Ca}^{2+}\right]$. In this experiment the concentration of $\mathrm{Ca}^{2+}$ for half-maximal effect was estimated to be $0.49 \mathrm{mM}$ and the maximal off-rate was estimated to be $4.7 \times 10^{-2} \mathrm{~s}^{-1}$; the dissociation rate in RBMn was $5.8 \times 10^{-4} \mathrm{~s}^{-1}$, there was no change in the dissociation rate in RB0 (not shown). For three experiments the concentration of $\mathrm{Ca}^{2+}$ for half-maximal effect was $0.37 \pm 0.1 \mathrm{mM}($ mean $\pm \mathrm{SD})$. 


\section{Figure 8 The effect of $\mathrm{Ca}^{2+}$ on the dissociation of integrin-FN complexes can be overcome by $\mathrm{Mn}^{2+}$ but not $\mathrm{Mg}^{2+}$.}

A, B. Binding of $\alpha \mathrm{V} \beta 3$ (A) or $\alpha 5 \beta 1-\mathrm{Fc}$ (B) to $50 \mathrm{~K}$ took place for $120 \mathrm{~s}$ in four parallel channels in RBMn, followed by buffer injection for $60 \mathrm{~s}$. At the time indicated by the downward pointing arrow (approx. $207 \mathrm{~s}$ ) either RBMn (red sensorgram), or RB0 with 0.2 $\mathrm{mM} \mathrm{Ca}^{2+}$ (cyan sensorgram), or RB0 with $0.2 \mathrm{mM} \mathrm{Ca}^{2+}$ and $1 \mathrm{mM} \mathrm{Mn}^{2+}$ (blue sensorgram), or RB0 with $0.2 \mathrm{mM} \mathrm{Ca}^{2+}$ and $5 \mathrm{mM} \mathrm{Mg}^{2+}$ (green sensorgram) was injected for approx. $120 \mathrm{~s}$. $\mathrm{C}$, D Binding of $\alpha \mathrm{V} \beta 3$ (C) or $\alpha 5 \beta 1-\mathrm{Fc}$ (D) to $50 \mathrm{~K}$ took place for $120 \mathrm{~s}$ in four parallel channels in RBMn, followed by injection of the same buffer for $60 \mathrm{~s}$. At the time indicated by the downward pointing arrow (approx. $207 \mathrm{~s}$ ) either RBMn (red sensorgram), or RB0 with $0.2 \mathrm{mM} \mathrm{Ca}^{2+}$ (cyan sensorgram), or RB0 with $0.2 \mathrm{mM} \mathrm{Ca}^{2+}$ plus varying concentrations of $\mathrm{Mn}^{2+}$ (as indicated on the other sensorgrams) was injected for approx. $120 \mathrm{~s}$. In panel $\mathrm{C}$ the concentration of $\mathrm{Mn}^{2+}$ for $50 \%$ recovery of the dissociation rate in $\mathrm{Mn}^{2+}$ alone was estimated by curve fitting to be $0.076 \mathrm{mM}$. For three experiments the concentration of $\mathrm{Mn}^{2+}$ for $50 \%$ recovery of the dissociation rate in $\mathrm{Mn}^{2+}$ alone was $0.077 \pm 0.011 \mathrm{mM}$ (mean $\pm \mathrm{SD}$ ). In panel $\mathrm{D}$ the concentration of $\mathrm{Mn}^{2+}$ for $50 \%$ recovery of the dissociation rate in $\mathrm{Mn}^{2+}$ alone was estimated to be $0.103 \mathrm{mM}$. For three experiments the concentration of $\mathrm{Mn}^{2+}$ for $50 \%$ recovery of the dissociation rate in $\mathrm{Mn}^{2+}$ alone was $0.103 \pm 0.015 \mathrm{mM}$ (mean $\pm \mathrm{SD}$ ). Data for $0.2 \mathrm{mM}$ $\mathrm{Ca}^{2+}$ plus $1 \mathrm{mM} \mathrm{Mn}^{2+}$ (not shown) were also included in the estimation of the concentration of $\mathrm{Mn}^{2+}$ for $50 \%$ recovery of the dissociation rate in $\mathrm{Mn}^{2+}$ alone.

\section{Figure 9 The effect of $\mathrm{Ca}^{2+}$ on the dissociation of $\alpha 5 \beta 1-\mathrm{FN}$ complexes can be overcome by the activating mAb TS2/16, or mimicked by the inhibitory mAb 13.}

A, Binding of $\alpha 5 \beta 1-\mathrm{Fc}$ to $50 \mathrm{~K}$ took place for $120 \mathrm{~s}$ in four parallel channels in the presence of a Fab fragment of N29 (red and cyan sensorgrams) or TS2/16 (blue and green sensorgrams) in RBMn, followed by injection of the same buffer alone for $60 \mathrm{~s}$. The concentration of $\alpha 5 \beta 1-$ Fc was 3nM in buffer alone or with N29 Fab, or $7.5 \mathrm{nM}$ with TS2/16 Fab fragment. At the time indicated by the downward pointing arrow (approx. $207 \mathrm{~s}$ ) either RBMn (red and blue sensorgrams), or RB0 with $0.2 \mathrm{mM} \mathrm{Ca}^{2+}$ (cyan and green sensorgrams) was injected for approx. $120 \mathrm{~s}$. In the experiment shown the dissociation rate of $\alpha 5 \beta 1-\mathrm{N} 29-\mathrm{FN}$ complexes in $\mathrm{Mn}^{2+}$ was $7.4 \times 10^{-4} \mathrm{~s}^{-1}$, the rate in $0.2 \mathrm{mM} \mathrm{Ca}^{2+}$ was $56 \times 10^{-4} \mathrm{~s}^{-1}$; the dissociation rate of $\alpha 5 \beta 1-\mathrm{TS} 2 / 16-\mathrm{FN}$ complexes in $\mathrm{Mn}^{2+}$ was $1.2 \times 10^{-4} \mathrm{~s}^{-1}$, the rate in $0.2 \mathrm{mM} \mathrm{Ca}^{2+}$ was $7.6 \times 10^{-}$ ${ }^{4} \mathrm{~s}^{-1}$. In the same experiment (sensorgrams not shown) the dissociation rates of $\alpha 5 \beta 1-\mathrm{FN}$ complexes in the absence of Fab fragments were essentially identical to those of $\alpha 5 \beta 1$ N29-FN complexes.

$\mathrm{B}$, Binding of $\alpha 5 \beta 1-\mathrm{Fc}$ to $50 \mathrm{~K}$ was allowed to occur for $120 \mathrm{~s}$ in three parallel channels in RBMn, followed by injection of the same buffer for $60 \mathrm{~s}$. At the time indicated by the downward pointing arrow (approx. 207 s) either RBMn alone (red sensorgram), or RBMn with $67 \mathrm{nM}$ mAb 13 (blue sensorgram), or RB0 with $0.2 \mathrm{mM} \mathrm{Ca}^{2+}$ (cyan sensorgram), was injected for approx. $120 \mathrm{~s}$. In the experiment shown the dissociation rate of $\alpha 5 \beta 1-\mathrm{FN}$ complexes was $6.9 \times 10^{-4} \mathrm{~s}^{-1}$, the dissociation rate of $\alpha 5 \beta 1-\mathrm{FN}$ complexes in the presence of $\mathrm{mAb} 13$ was $55 \times 10^{-4} \mathrm{~s}^{-1}$, the rate in $0.2 \mathrm{mM} \mathrm{Ca}^{2+}$ was $57 \times 10^{-4} \mathrm{~s}^{-1}$. 


\section{TABLES}

Table 1. Dissociation rates of integrin-FN complexes during the early and late stages of the dissociation phase.

\begin{tabular}{lcr}
\hline Integrin & $\mathrm{k}_{\mathrm{d} \text {-early }}\left(10^{-3} \mathrm{~s}^{-1}\right)$ & $\mathrm{k}_{\mathrm{d}-\text { late }}\left(10^{-3} \mathrm{~s}^{-1}\right)$ \\
$\alpha 5 \beta 1-\mathrm{Fc}$ & $0.72 \pm 0.01$ & $0.30 \pm 0.02$ \\
$\operatorname{rs} \alpha \mathrm{V} \beta 1$ & $3.82 \pm 0.06$ & $0.88 \pm 0.07$ \\
$\alpha \mathrm{V} \beta 3 \Delta \mathrm{TM}$ & $0.55 \pm 0.02$ & $0.22 \pm 0.05$ \\
$\operatorname{rs} \alpha \mathrm{V} \beta 6$ & $2.02 \pm 0.03$ & $0.71 \pm 0.02$ \\
$\mathrm{TR} \alpha 5 \beta 1-\mathrm{Fc}$ & $3.43 \pm 0.07$ & $0.11 \pm 0.01$
\end{tabular}

$\mathrm{k}_{\mathrm{d} \text {-early }}$ was estimated by curve-fitting for the first $200 \mathrm{~s}$ of the dissociation phase, $\mathrm{k}_{\mathrm{d}-\mathrm{late}}$ for the final 500s of the dissociation phase. Mean and standard deviation of three experiments are shown. 


\section{FIGURES}

Figure 1
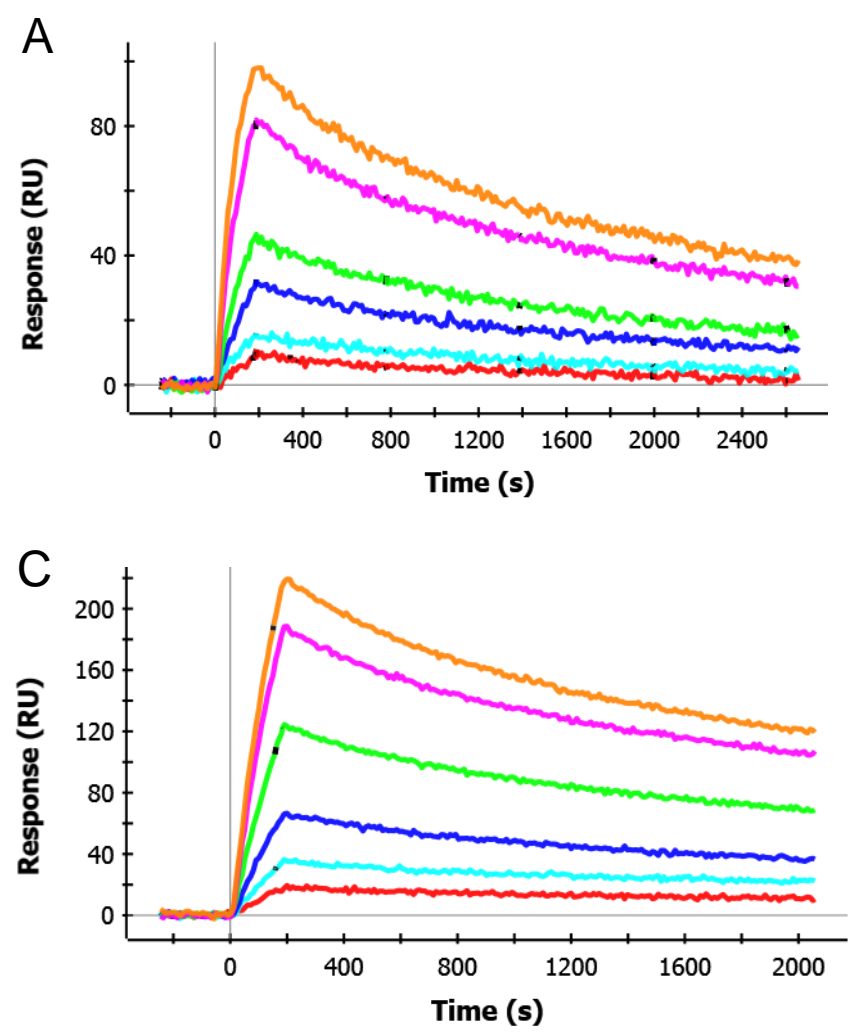
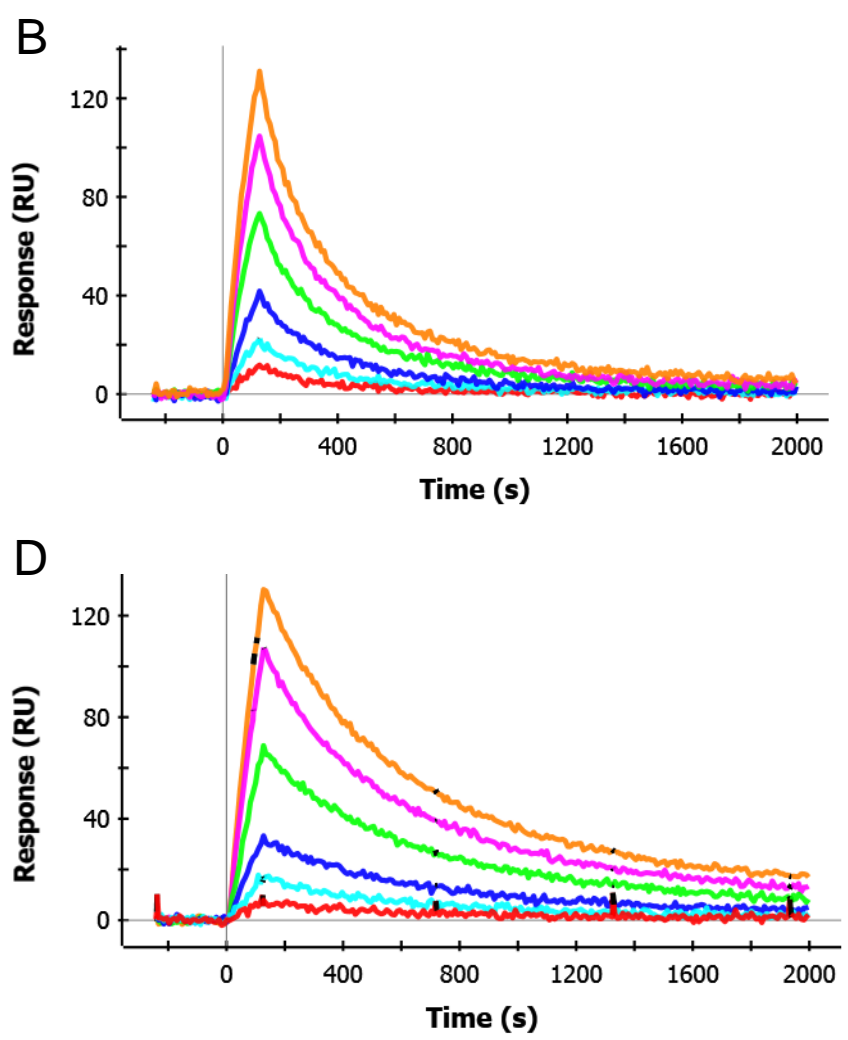
Figure 2
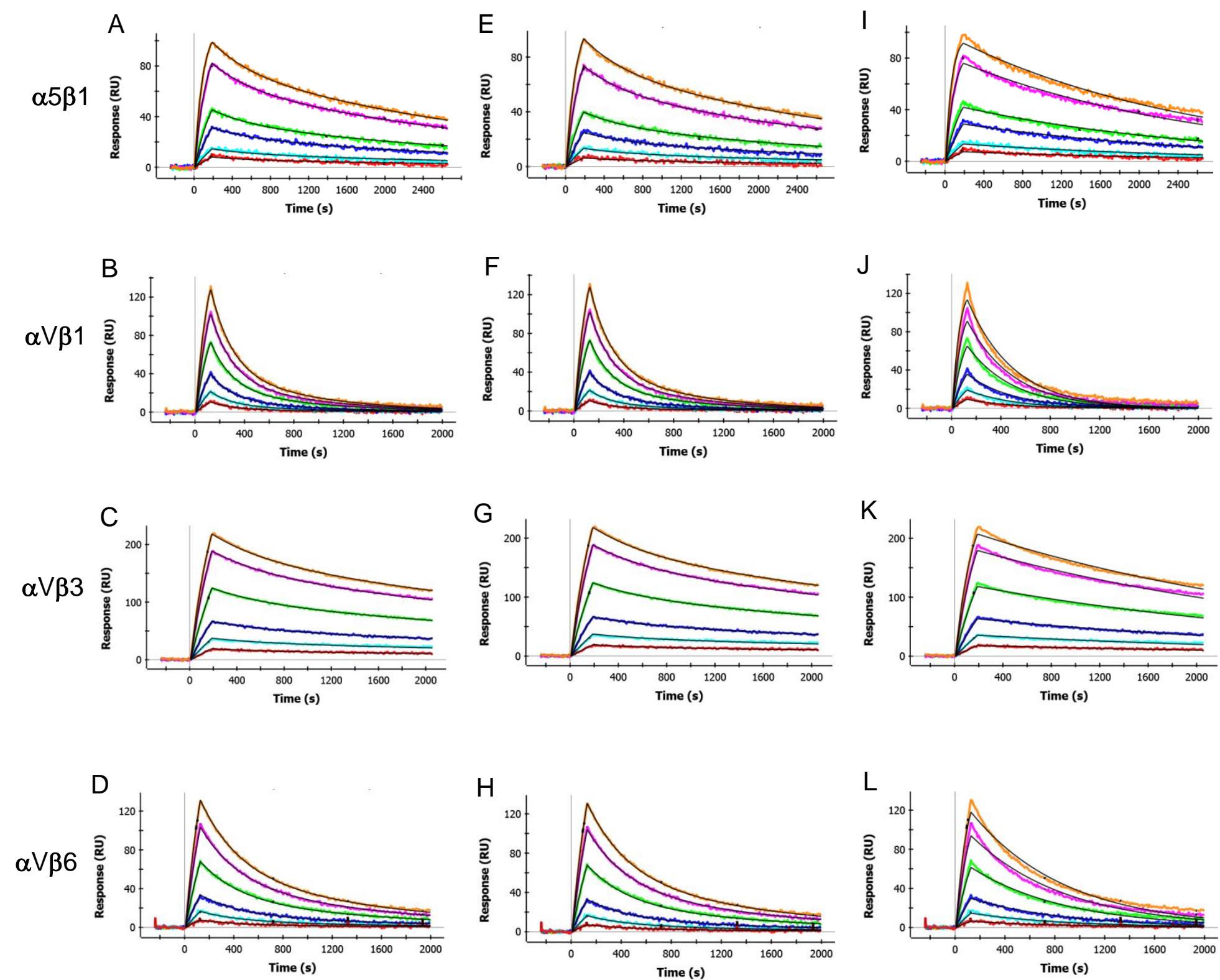
Figure 3

Cilengitide
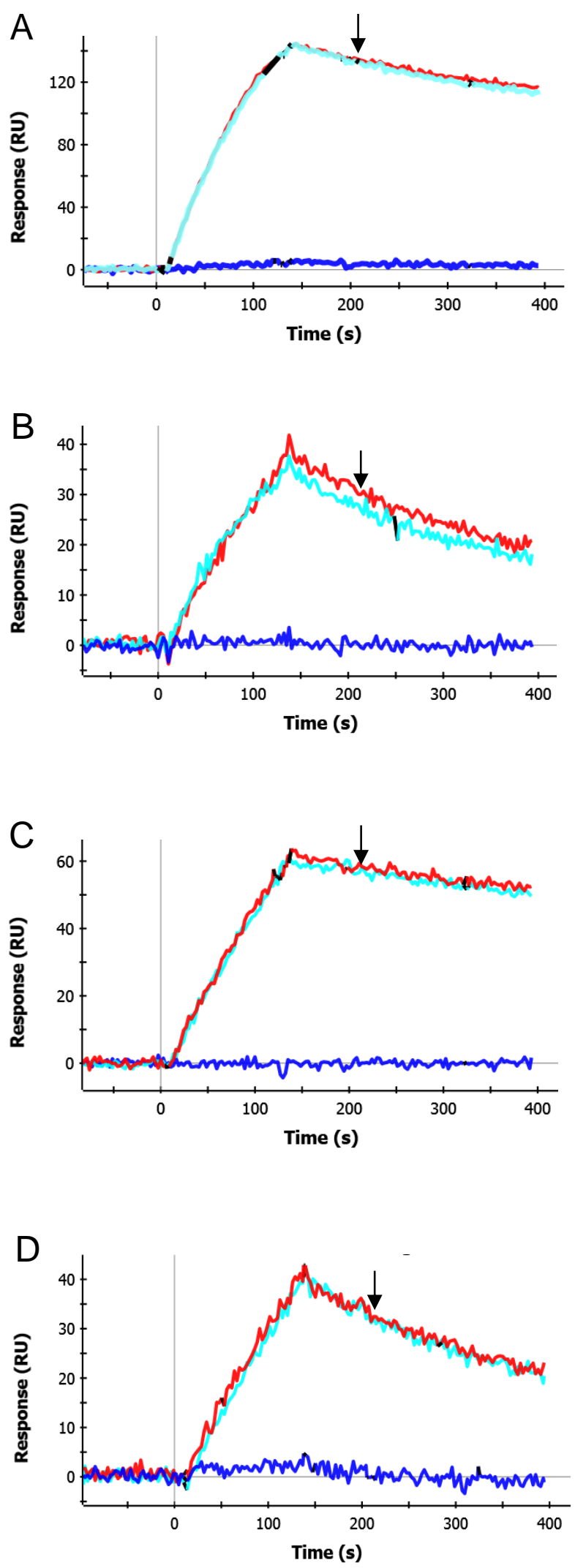

CRGD
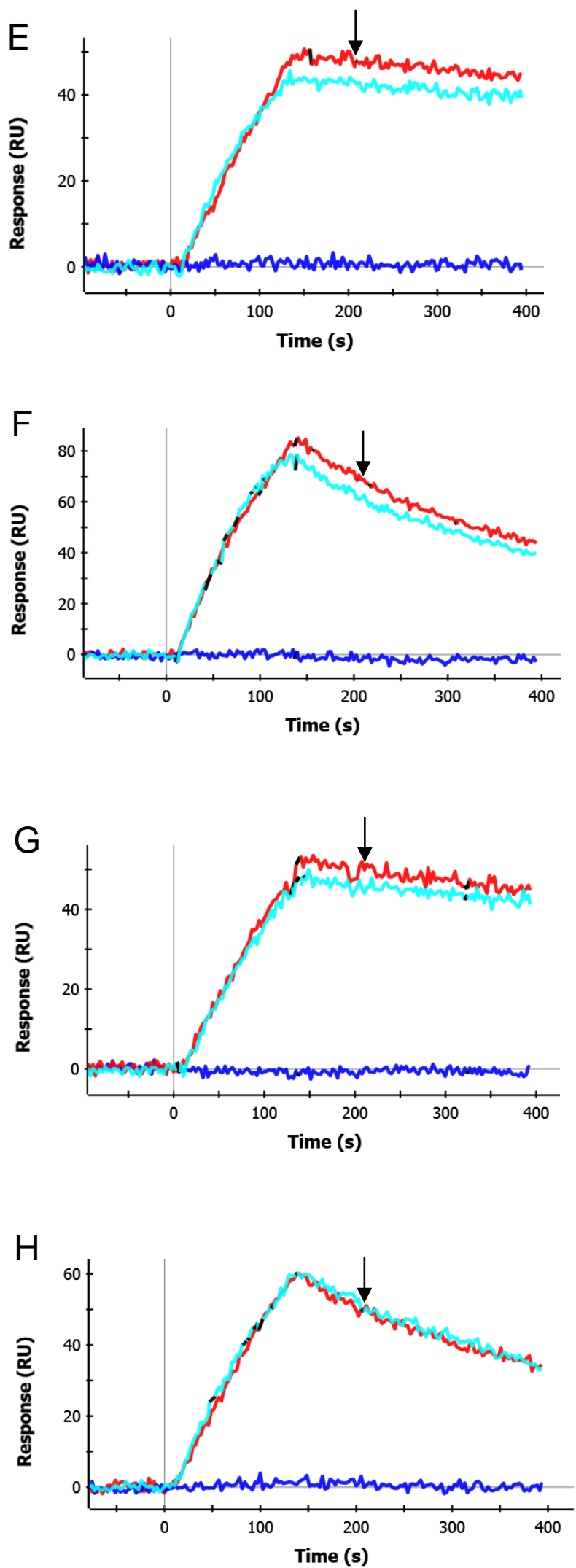
Figure 4
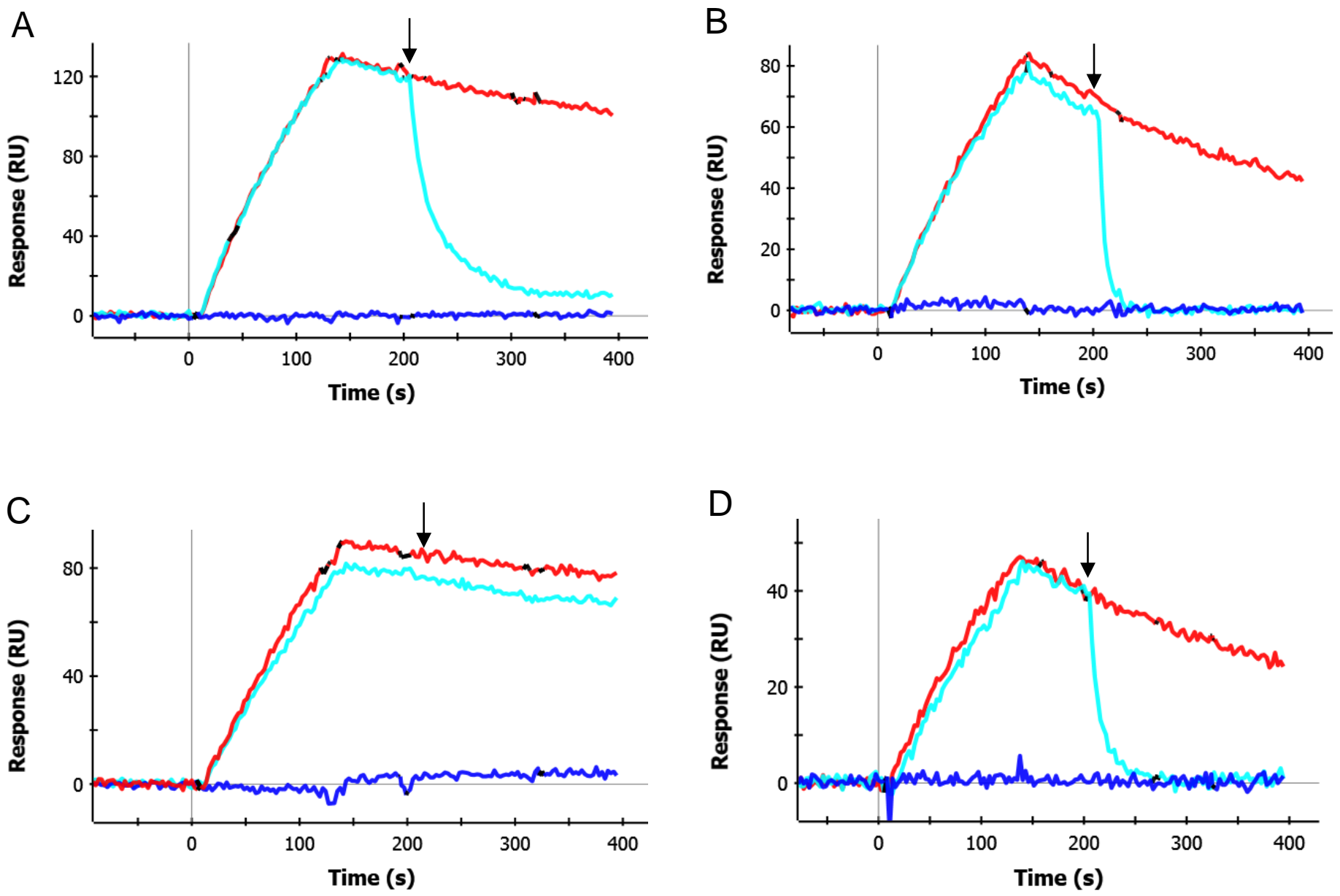
Figure 5
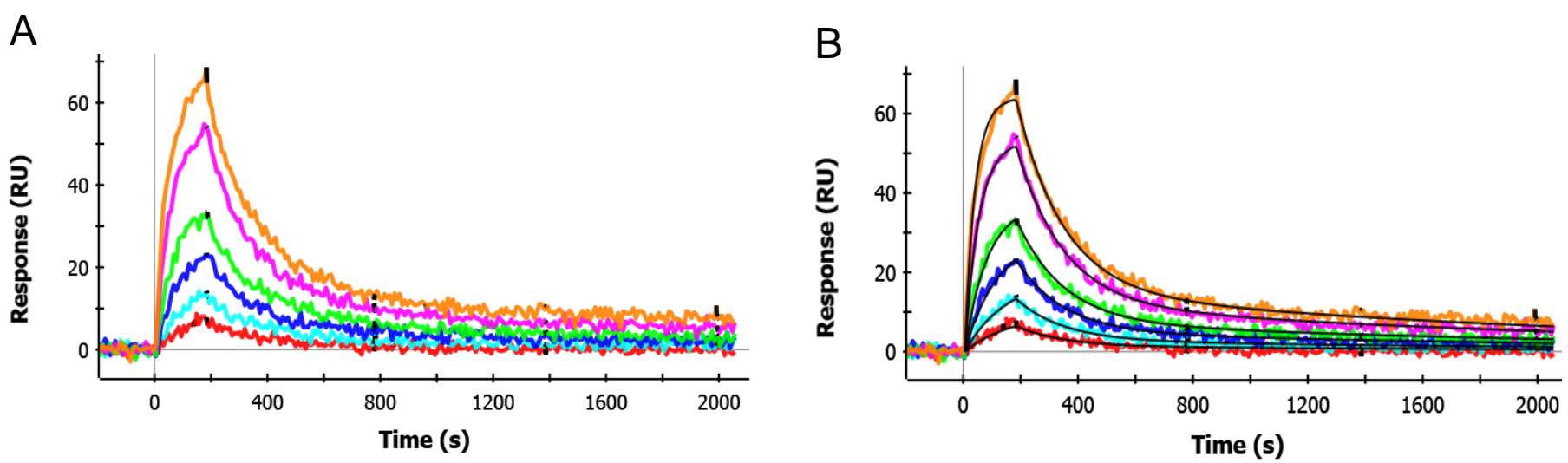

C
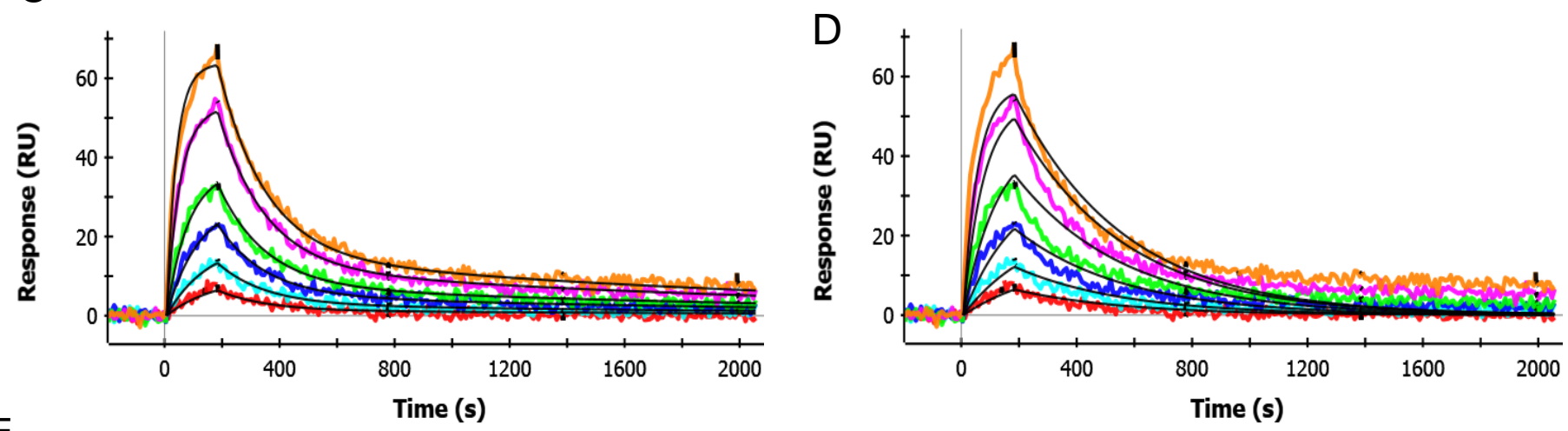

E
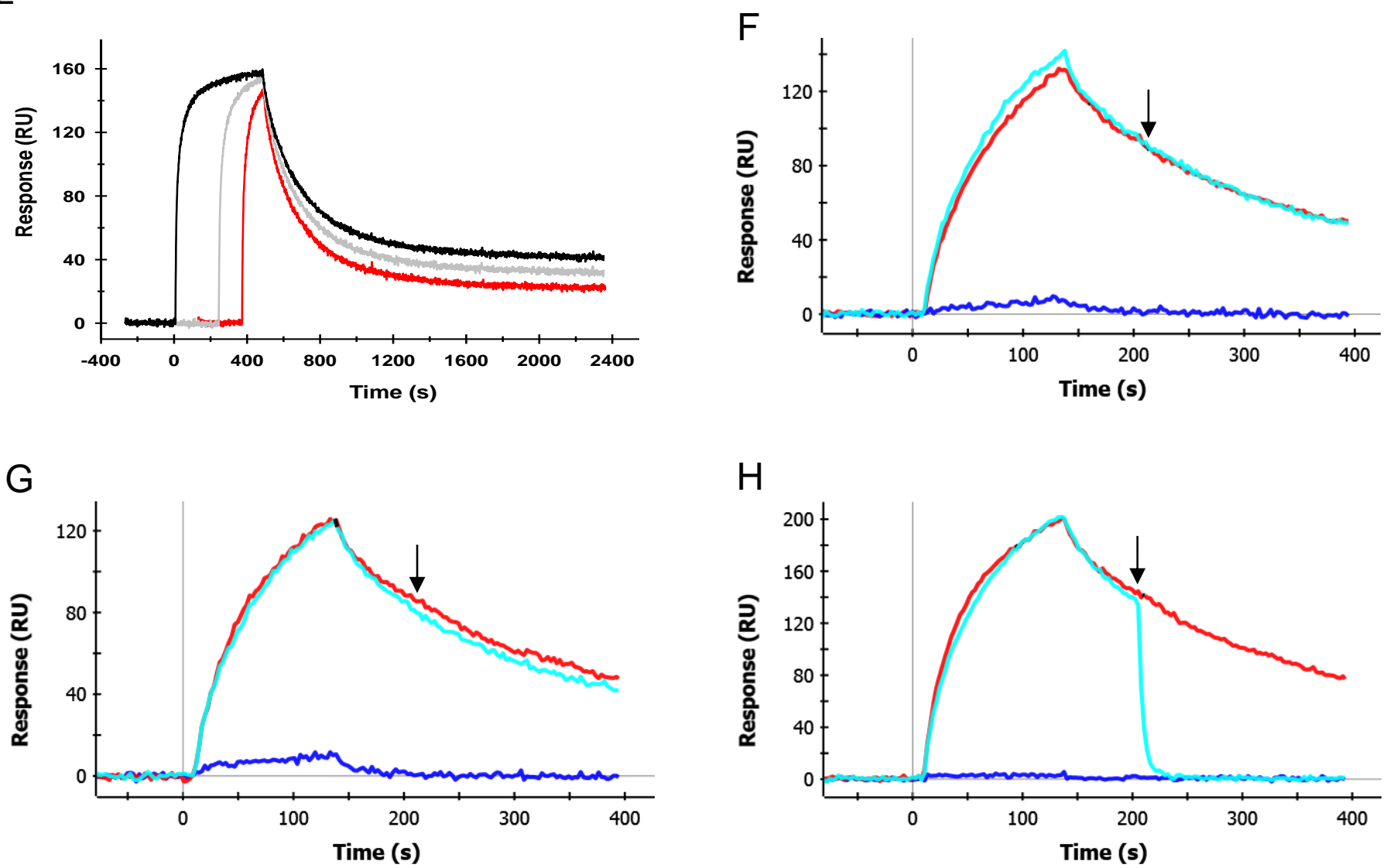
Figure 6
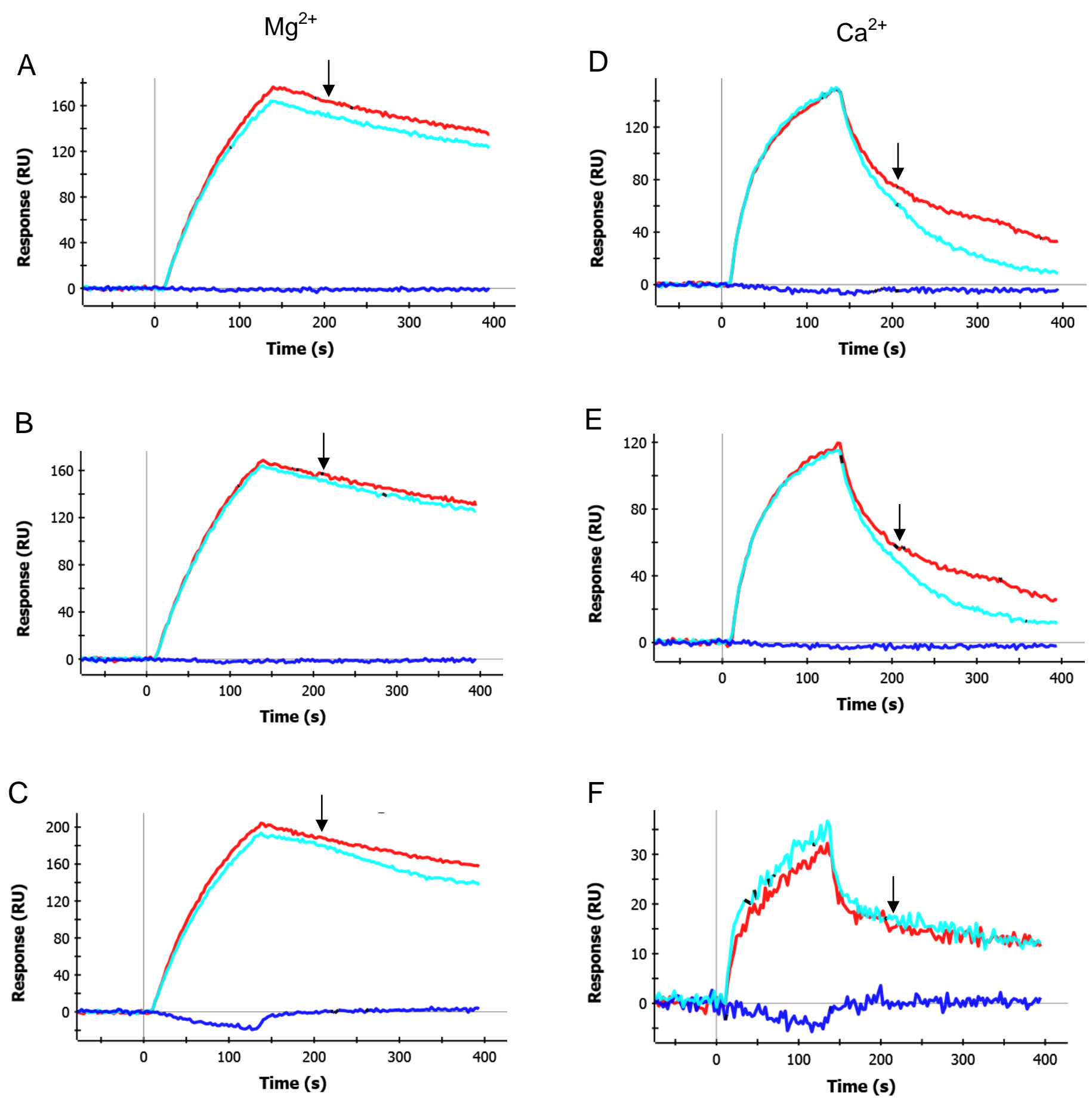
Figure 7
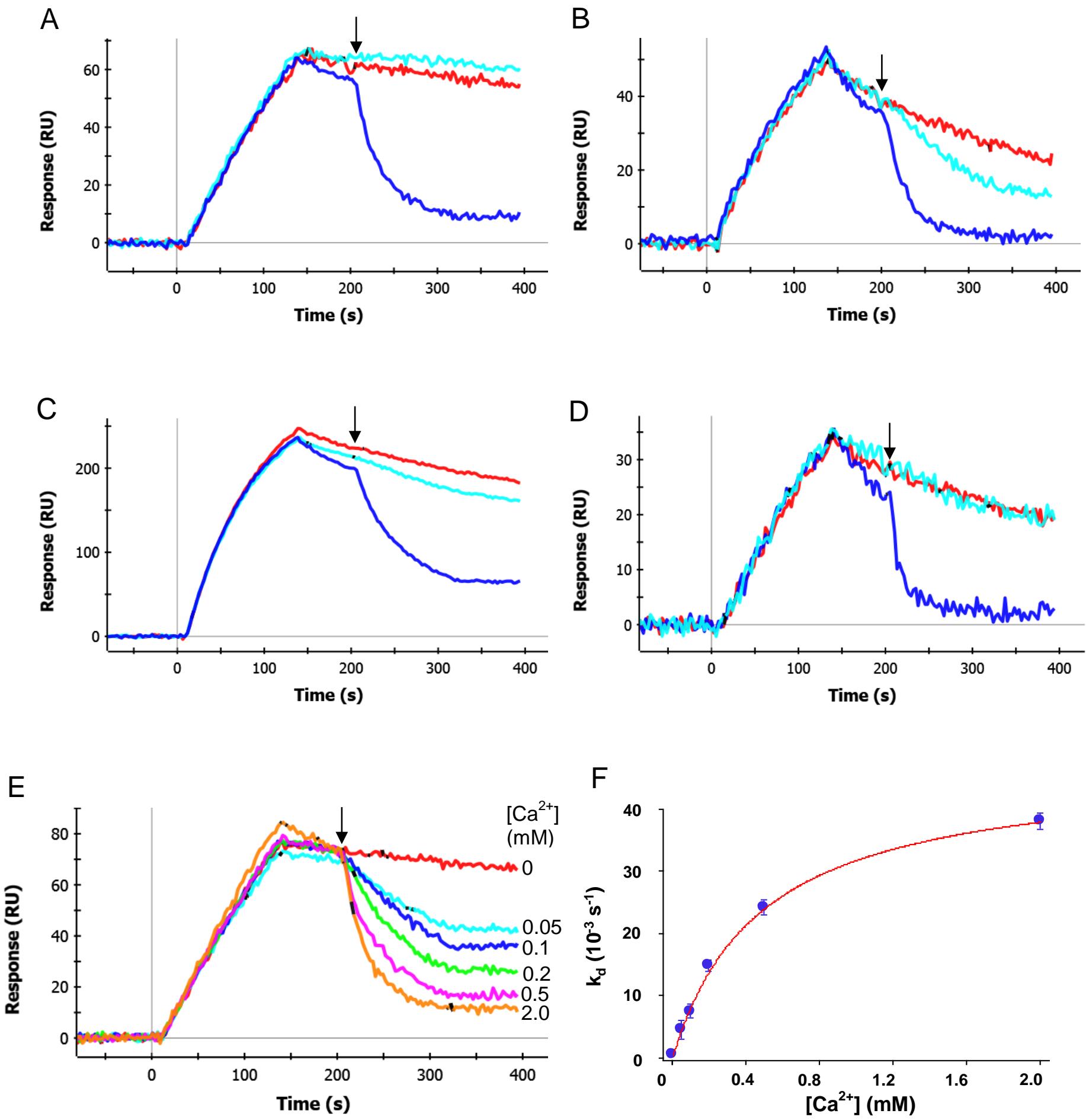
Figure 8
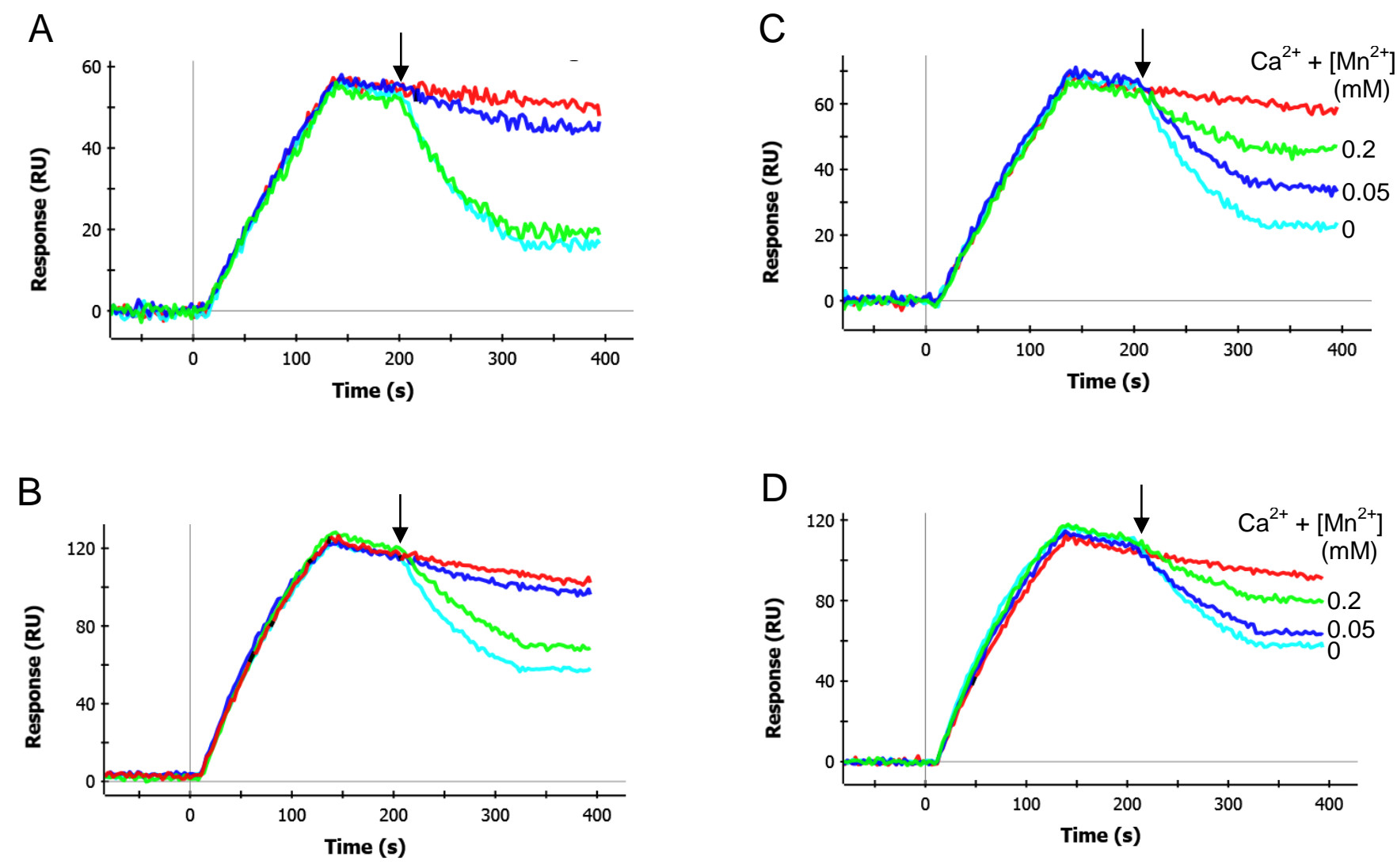
Figure 9
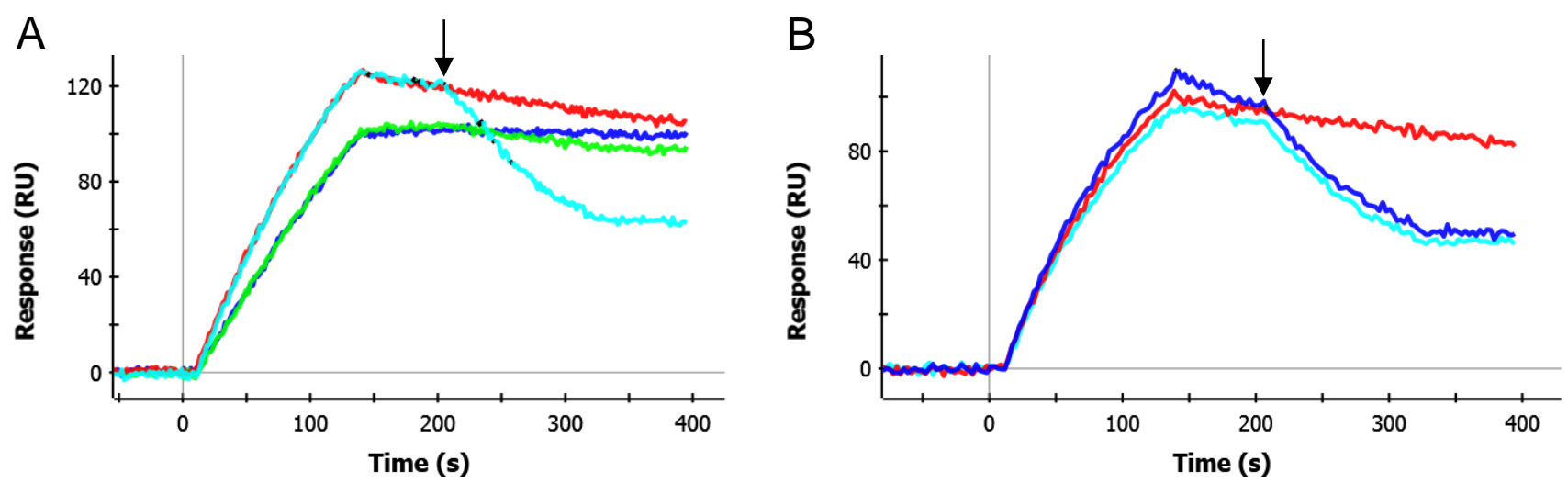